Cuadernos de Historia Moderna

ISSN: 0214-4018

https://dx.doi.org/10.5209/chmo.72066

\title{
Luis Carduchi, de pintor a Catedrático de Matemáticas y Artillería ${ }^{1}$
}

\author{
Margarita Ana Vázquez Manassero²
}

Recibido: 12 de octubre de 2020 / Aceptado 27 de abril de 2021

Resumen. En este artículo se lleva a cabo una reconstrucción de la escasamente conocida trayectoria de Luis Carduchi (Madrid, ca. 1596-1657), hijo y sobrino de los pintores florentinos, Bartolomé y Vicente Carducho, respectivamente. Del estudio de la documentación de archivo, así como de su producción cartográfica y científica, emerge una interesante evolución profesional: desde sus inicios como pintor, pasando después a ejercer como agrimensor y matemático, hasta llegar a ocupar la Cátedra de Matemáticas y Artillería. Para comprender esta evolución profesional se analizarán asimismo las estrategias de promoción social de las que se valió Carduchi en la corte buscando el favor de la parentela del conde-duque de Olivares así como del propio valido. Al mismo tiempo, la integración entre artes y ciencias que caracterizó la labor y los escritos de Carduchi permitirá explorar las imbricaciones que existieron entre esas esferas del saber en la España del siglo XVII.

Palabras clave. Luis Carduchi; imbricaciones arte-ciencia; corte española; conde-duque de Olivares; Felipe IV.

\section{[en] Luis Carduchi: from painter to Professor of Mathematics and Artillery}

Abstract. This article presents a reconstruction of Luis Carduchi's little-known career (Madrid, ca. 1596-1657). Carduchi was son and nephew of the Florentine painters, Bartolomé and Vicente Carducho, respectively. From the analysis of archival documentation, as well as from his cartographic and scientific production, an interesting professional evolution emerges: he started as a painter, then worked as a surveyor and mathematician, and finally he reached the Chair of Mathematics and Artillery. To understand Carduchi's progress, the social promotion strategies he used at the Spanish Court will also be analyzed: he managed to get the favor of Count-Duke of Olivares, first through valido's relatives' and then the valido itself. Besides, Carduchi's work and writings were characterized by the integration between arts and sciences, which will allow us to explore the connections between both spheres of knowledge in $17^{\text {th }}$ century Spain.

Keywords. Luis Carduchi; art and science overlaps; Spanish Court; Count-Duke of Olivares; Philip IV.

Sumario: Los inicios. Luis Carduchi, pintor y su relación con los artistas del Madrid de la primera mitad del siglo XVII. El ascenso cortesano y la autoconstrucción profesional de Luis Carduchi: dimensor, matemático, juez para medir jurisdicciones de Felipe IV, ingeniero y arquitecto militar. El zénit. Luis Carduchi, Catedrático de Matemáticas y Artillería del Consejo de Guerra. Bibliografía.

1 Esta investigación se ha desarrollado en el marco del proyecto I+D "El dibujante ingeniero al servicio de la monarquía hispánica. Siglos XVI-XVIII: ciudad e ingeniería en el Mediterráneo", ref. HAR2016-78098-P (AEI/FEDER, UE), financiado por la Agencia Estatal de Investigación (Ministerio de Economía, Industria y Competitividad) y el Fondo Europeo de Desarrollo Regional (FEDER).

2 Departamento de Historia y Teoría del Arte. Facultad de Filosofía y Letras. Universidad Autónoma de Madrid. E-mail: margarita.vazquez@uam.es

ORCID: https://orcid.org/0000-0002-8957-8479 
Cómo citar: Vázquez Manassero, M. A. (2021). Luis Carduchi, de pintor a Catedrático de Matemáticas y Artillería, en Cuadernos de Historia Moderna 46.1, 147-174.

La trayectoria vital y profesional de Luis Carduchi (Madrid, ca. 1596-1657) ${ }^{3}$ estuvo marcada por la integración entre artes y ciencias, una característica heredera de la tradición cultural del Renacimiento italiano $\mathrm{s}^{4}$, lo que le convierte en un interesante caso de estudio para explorar las imbricaciones entre esas esferas del saber en la España del siglo XVII.

Luis Carduchi fue hijo del pintor florentino Bartolomé Carducho (Florencia, ca. 1560 - Madrid, 1608) y sobrino del también pintor y tratadista Vicente Carducho (Florencia, ca. 1576 - Madrid, 1638). Si bien sus relaciones de parentesco son bien conocidas por la historiografía, las aproximaciones a su personalidad y a su obra han sido, por lo general, de carácter parcial e, incluso, tangencial. Por una parte, desde el ámbito de la Historia del Arte, las referencias a Luis Carduchi han estado siempre supeditadas a su condición de "hijo de" o "sobrino de", Bartolomé y Vicente, respectivamente ${ }^{5}$. Por otro lado, las publicaciones sobre Historia de la cartografía e Historia de la Ciencia, se han centrado principalmente en el estudio de las dos obras más conocidas que escribió: los Elementos geometricos de Evclides philosopho megarense. Svs seys primeros libros (Alcalá de Henares, 1637) y la Chorografia del río Tajo (1641), un atlas manuscrito del que se conservan diferentes ejemplares ${ }^{6}$.

\footnotetext{
En la bibliografía relativa a Luis Carduchi que a continuación se va a referir, el apellido de este artífice aparece transcrito de diversas formas (Carducci, Carducho o Carduchi). En este artículo se ha adoptado la transcripción "Carduchi" puesto que en los numerosos documentos manuscritos firmados de su puño y letra que aquí se van a analizar, su firma autógrafa es siempre "Luis Carduchi".

4 Burke, P.: El Renacimiento italiano. Cultura y sociedad en Italia, Madrid, Alianza, 2001, pp. 35 y ss.

5 Entre los documentos relativos a los hermanos Bartolomé y Vicente Carducho dados a conocer por M. Agulló y Cobo, menudean algunas referencias a Luis Carduchi: Agulló y Cobo, M.: Documentos para la historia de la pintura española, vol. 1, Madrid, Museo del Prado, 1994, pp. 16-18; Agulló y Cobo, M.: Documentos para la historia de la pintura española, vol. 2, Madrid, Museo del Prado, 1996, pp. 17-19. Posteriormente, M. Lapuerta Montoya incluyó una breve reseña biográfica sobre Luis Carduchi en el contexto más amplio de su análisis de la labor desempeñada por su padre y su tío en la decoración del palacio de El Pardo: Lapuerta Montoya, M.: Los pintores de la corte de Felipe III: la Casa Real de El Pardo, Madrid, Fundación Caja Madrid, 2002, pp. 261-262.
}

${ }_{6}$ E. Llaguno dedicó unos pocos renglones a Carduchi y la información suministrada se basa fundamentalmente en la mención que de él realiza su tío Vicente en los Diálogos de la pintura (1633): Llaguno y Amírola, E.: Noticias de los arquitectos y arquitectura de España desde su restauración, por el Excmo. Señor D. Eugenio Llaguno y Amirola, ilustradas y acrecentadas con notas, adiciones y documentos por D. Juan Agustín Ceán-Bermúdez, vol. 4, Madrid, Imprenta Real, 1829, pp. 19-20. J. Almirante situaba a Carduchi como autor de la Chorografia del río Tajo y dio noticia de un memorial fechado en 1650 donde el autor declaraba ser matemático, arquitecto militar y uno de los jueces nombrados para medir jurisdicciones: Almirante, J.: Bibliografia militar de España, Madrid, Imprenta y Fundición de Manuel Tello, 1876, pp. 116-117. A finales del siglo XIX, F. Picatoste afirmaba que L. Carduchi nació en Madrid y se formó con Julio César Firrufino en la Academia de Matemáticas situada entonces en casa del marqués de Leganés, siendo autor de dos tratados impresos: Como se deven medir las ivrisdiciones (1634) y Elementos geometricos de Evclides (1637): Picatoste, F.: Apuntes para una biblioteca cientifica española del siglo XVI: estudios biográficos y bibliográficos de ciencias exactas, fisicas y naturales y sus inmediatas aplicaciones en dicho siglo, Madrid, Imprenta y Fundición de Manuel Tello, 1891, pp. 3738. Más recientemente, fueron publicadas sendas voces biográficas de este personaje en: Navarro Brotóns, V.: "Carduchi, Luis", en López Piñero, J. M. y otros.: Diccionario histórico de la ciencia moderna en España, vol. 1, Barcelona, Península, 1983, pp. 180-181; y Esteban Piñeiro, M.: "Carduchi, Luis”, en Silva Suárez, M. (ed.): Técnica e ingeniería en España. El Renacimiento. De la técnica imperial y la popular, vol. 1, Zaragoza, Real Academia de Ingeniería-Institución "Fernando el Católico" - Prensas Universitarias de Zaragoza, 2008, p. 710. 
Un estudio de la abundante documentación de archivo generada por Luis Carduchi, así como la interpretación de su producción cartográfica y científica en el marco del escenario cortesano en el que esta germinó, va a proporcionar un mejor conocimiento de esta figura todavía bastante oscura. Del análisis de estos materiales emerge un interesante proceso de construcción profesional: desde los inicios de Carduchi como estudiante en la Universidad de Salamanca y pintor, pasando después a ejercer como agrimensor, llegando finalmente a ocupar la Cátedra de Matemáticas y Artillería de Su Majestad dependiente del Consejo de Guerra durante los últimos años de su vida ${ }^{7}$. Además, teniendo en cuenta su filiación familiar y cultural, Luis Carduchi participó en uno de los debates que más ríos de tinta hicieron correr en la corte española entre los artistas, literatos y humanistas de la época: la defensa de la liberalidad de las artes. Así, en el proemio de su tratado Elementos geometricos de Evclides publicado en 1637, Luis Carduchi declaraba lo siguiente:

[...] y ojala se introduxera por precepto inuiolable, que assi como los Reyes, señores, y toda la nobleza acostumbra en la infancia de sus hijos enseñarles la gramatica, enseñaran tambien estas sciencias acompañadas con el dibujo operatiuo que es la llaue maestra de todas ellas, [...] es introductor, y lengua al entendimie[n]to: Federico Zucaro le figuro en vn geroglifico assi pinto vna canterna corrido el rallo, y por el alumbraua a las sciencias, y las Artes, saliendo por cada agujero vn vivo rayo de luz que cria a cada vna dellas, y fue bien acetado en las academias de Italia. En las Artes, que vale la teorica sola sin la pratica, mayormente la pintura, en quien dandose las manos fuesen marauillosos efectos, como lo han mostrado valiente, y doctamente los artífices de los tiempos passados y en los nuestros entre otros los dos hermanos Bartolome y Vicencio Carduchi tan conocidos y celebrados por sus obras assi en estos Reynos, como en los estraños, en quien lucieron todas las partes que deue tener vn docto pintor $[\ldots]^{8}$.

Los renglones apenas citados bien podrían haber formado parte de un tratado en defensa de la liberalidad de la pintura; un debate en pleno apogeo durante la década

La edición de Carduchi de los Elementos ha sido analizada por: Vicente Maroto, M. I., Esteban Piñeiro, M.: Aspectos de la ciencia aplicada en la España del Siglo de Oro, Valladolid, Junta de Castilla y León-Consejería de Cultura y Turismo, 2006, pp. 228-229 y 231. El proyecto de Carduchi para la navegación del río Tajo, junto con otras propuestas de ingeniería hidráulica diseñadas para idéntico fin, han sido estudiadas por: López Gómez, A.: La navegación por el Tajo. El reconocimiento de Carduchi y otros proyectos, Madrid, Real Academia de la Historia, 1998. La copia del ejemplar de la Chorografia de Carduchi conservada en el Archivo Municipal de Toledo ha sido objeto de la siguiente edición crítica: Carducho, L.: Chorografia del rio Tajo: año de 1641, 2 vols., Toledo, Ayuntamiento de Toledo, 2008. Su labor como agrimensor fue brevemente analizada por: Buisseret, D.: "Spanish Peninsular Cartography, 1500 - 1700", en Woodward, D. (ed.): Cartography in the European Renaissance, vol. 3, part 1, Chicago-Londres, The University of Chicago Press, 2007, pp. 1076-1077.

7 Como han señalado M. I. Vicente Maroto y M. Esteban Piñeiro no debe confundirse esta Cátedra de Matemáticas y Artillería, dependiente del Consejo de Guerra, cuyo origen y finalidad principal residía en la necesidad de formar en las matemáticas y en las disciplinas de ella derivadas a ingenieros militares y artilleros; con la Cátedra de Matemáticas y Cosmografía, de carácter estrictamente cosmográfico y náutico, dependiente del Consejo de Indias: Vicente Maroto, Esteban Piñeiro, op. cit. (nota 6), pp. 178-180.

8 Carduchi, L.: Elementos geometricos de Evclides philosopho megarense. Svs seys primeros libros. Al Ex[celenetisi]mo S[eño]r D. Gaspar de Gvzman Conde de Olibares dvcq[ue] de S. Lvcar la Mayor camarero y caballeriço mayor de Sv Mag[estad] \& Traducido el texto y comentado por Lvis Cardvchi Mathematico de Su Magestad, Alcalá de Henares, Por Antonio Duplast, 1637, sin foliar. 
de $1630^{\circ}$. No en vano, tan solo cuatro años antes de que Luis Carduchi publicase los Elementos geometricos de Evclides, vieron la luz los Diálogos de la pintura. Su defensa, origen, esencia, definición, modos y diferencias (1633) donde su tío Vicente postulaba una idea análoga del docto pintor ${ }^{10}$. De este modo, los elogiosos términos en los que Luis ensalza tanto a su padre como a su tío, así como la referencia al pintor Federico Zuccaro con quienes los Carducho mantuvieron una estrecha relación ${ }^{11}$, no solo defendían los intereses familiares sino que también nos hablan del milieu cultural en el que Luis creció y se formó.

\section{Los inicios. Luis Carduchi, pintor y su relación con los artistas del Madrid de la primera mitad del siglo XVII}

El lapso de tiempo que media entre el año 1596 -fecha en que Luis Carduchi fue bautizado en la madrileña parroquia de San Sebastián ${ }^{12}-$ y los primeros años de la década de 1630, constituyen un periodo hasta la fecha desconocido en la trayectoria de este artífice. A este respecto, la documentación notarial aquí estudiada aporta algo de luz. En 1614, cuando Luis Carduchi debía contar con unos 18 años de edad, otorgó una carta de pago fechada en Madrid a 14 de mayo de dicho año en la que declaraba ser "estudiante matriculado en Vniberssidad de salamanca hixo de bartolome carducho difunto y dona ger[oni]ma capelo sus padres rresidente en esta corte como donatario ques de la $\mathrm{d}[\mathrm{ic}] \mathrm{ha}$ dona Ger[oni]ma capelo y ella cesonario de bicencio carducho tio del d $[i c]$ ho"13. En relación con su formación salmantina, esta es la única referencia a la misma que se ha podido localizar, por lo que se desconoce el programa de estudios que pudo haber cursado en dicha Universidad. Tan solo unos meses más tarde, Luis Carduchi acudió nuevamente ante el notario para otorgar un poder para cobrar rentas que tenía por Su Santidad en el arzobispado de Granada donde declaraba ser "clérigo de menores" 14 . Sin embargo, parece que su carrera eclesiástica no fue demasiado prolongada y debió colgar pronto los hábitos puesto que en 1621 estaba ya casado con doña Mariana Bazán ${ }^{15}$; más tarde, en la década de 1640,

La bibliografía en torno a esta cuestión es muy amplia. Remitimos al lector a una de las obras que continúa siendo referencia sobre el tema: Gállego, J.: El pintor de artesano a artista, Granada, Universidad de Granada, 1976.

10 Carducho, V.: Diálogos de la Pintura. Su defensa, origen, esencia, definición, modos y diferencias. Edición, prólogo y notas de Francisco Calvo Serraller, Madrid, Ediciones Turner, 1979.

11 Moralejo Ortega, M.: “Zuccari and the Carduchos", en Andrews, J., Roe, J. y Noble Wood, O. (eds.): On Art and Painting. Vicente Carducho and Baroque Spain, Cardiff, University of Wales Press, 2016 pp. 205-221.

12 Mazón de la Torre, M. A.: "Las partidas de bautismo de Eugenio Cajés, de Félix Castelo, de los hermanos Rizi y otras noticias sobre artistas madrileños de la primera mitad del siglo XVII”, Archivo Español de Arte, 176 (1971), p. 416.

13 Carta de pago otorgada por Luis Carduchi, Madrid, 14 de mayo de 1614, Archivo Histórico de Protocolos de Madrid (AHPM), Protocolo (Prot.) 4.306, fol. 583r.

14 Poder de Luis Carduchi para cobrar rentas de Su Santidad, Madrid, 14 de octubre de 1614, AHPM, Prot. 4.426, fol. $1.486 \mathrm{r}$.

15 Carta de obligación de Luis Carduchi, pintor, que vive en la calle de la Ruda y doña Mariana Bazán, su mujer, Madrid, 26 de septiembre de 1621, AHPM, Prot. 5.064, fols. 537r.-539 v. En las referencias a Luis Carduchi contenidas en la historiografía, M. Lapuerta Montoya señala el matrimonio de Carduchi con Jerónima de Mendoza y, posteriormente, con Isabel de Benavides y Lamaestra. A estos dos matrimonios, habría que añadir las primeras nupcias que Carduchi contrajo con Mariana Bazán: Lapuerta Montoya, op.cit. (nota 5), pp. 261-262. 
estuvo desposado con doña Jerónima de Mendoza ${ }^{16} \mathrm{y}$, finalmente, en el momento de su muerte acaecida en 1657, su mujer era doña Isabel de Benavides y Lamaestra ${ }^{17}$.

Tras estas tempranas referencias de Carduchi como estudiante en Salamanca y clérigo de menores, en la documentación relativa al periodo comprendido entre los años 1621 y 1623, Luis declarará ser “pintor" de manera ininterrumpida. A su vez, en esas mismas fechas, se han podido documentar las frecuentes transacciones de Luis Carduchi con otros artífices relacionados con diferentes disciplinas artísticas. Todas estas cuestiones aparecen reflejadas en la carta de obligación de pago contraída el 26 de septiembre 1621 por Carduchi -pintor que vive en la calle de la Ruda en casas de Francisco de Vega- y su por aquel entonces esposa, doña Mariana Bazán, con el platero Angelo Palabesin. En ella, Carduchi y su mujer se obligaban a pagar 545 reales en reales de plata doble, a razón de un cabestrillo de oro esmaltado en blanco y negro $^{18}$. Para hacer frente al pago de tal cantidad los otorgantes hipotecaban "vna parte de casa de quatro que a mi el otorg[an]te [Luis Carduchi] pertenece de las dos casas que quedaron en esta u[illa] por fin y muerte de Bar[tolo]me Carducho y dona g[eroni]ma Capelo padres de mi el d[ic]ho Otorg[an]te" situadas en la calle de Atocha frente al convento de La Magdalena ${ }^{19}$.

Poco más de un año después, el pintor Luis Carduchi adquirió una casa situada en la calle del Olmo, junto a la parroquia de San Sebastián; una transacción en la que nuevamente se alude a la herencia de las casas de su padre, Bartolomé Carducho ${ }^{20}$, y en la que intervino su tío, Vicente ${ }^{21}$. En una de las cláusulas del documento se declaraba que la mitad de los 2.000 ducados de a once reales que valía el inmueble de la calle del Olmo adquirido por Luis fueron abonados por su tío Vicente, quien los tenía en su poder -suponemos que en calidad de curador de su sobrino-. Se trataba del dinero que le correspondía a Luis, como uno de los cuatro herederos de Bartolomé Carducho, tras la venta de las casas de la calle de Atocha que pertenecieron a su padre $^{22}$. Además, en este contrato de compraventa, algunos de los testigos implicados declaran dedicarse a oficios relacionados con el arte de la pintura, como es el caso del moledor de color Damián Adán o son personas vinculadas al entorno de la corte como Jacome Vautres, arquero de Su Majestad o Juan Bazán, escribano del rey ${ }^{23}$.

En esos primeros años de la década de 1620, Luis Carduchi-siempre en calidad de "pintor"- también mantuvo frecuentes contactos con comerciantes de todo tipo: el 23

16 Agulló y Cobo, op. cit. (nota 5, 1996), pp. 17-18.

17 Testamento de Luis Carduchi, catedrático de matemática de su Majestad, Madrid, 23 de febrero de 1657, AHPM, Prot. 6.681, fols. 920r.-923v. Un breve extracto de los contenidos de este testamento fue publicado por: Agulló y Cobo, op. cit. (nota 5, 1994), pp. 16-17.

18 Carta de obligación de Luis Carduchi, pintor, en favor del platero Angelo Palabesin, Madrid, 26 de septiembre de 1621, AHPM, Prot. 5.064, fols. 537r.-537v.

19 Ibidem, fols. 538r.-538v.

20 Sobre las casas que pertenecieron a Bartolomé Carducho en la calle de Atocha, M. Lapuerta, analiza una serie de documentos relativos a las mismas, fechados entre 1606 y 1621: Lapuerta Montoya, op. cit. (nota 5), pp. 252-253.

21 Venta de casa que otorgaron Ju[an] martinez y su mug[er] a Luis carduchi. Çenso otorgado por los dichos luis Caduchi y su mug[e]r al d[ic]ho Ju[an] Martinez y la suya de $1 \mathrm{U}$ d[ucado]s de pl[ata], Madrid, 17 de diciembre de 1622, AHPM, Prot. 5.065, fols. 188r.-201r.

22 Ibidem, fol. 189r.

23 Ibidem, fol. 200v. En esa misma fecha y ante el mismo escribano - Pedro de Ezcaray - Luis Carduchi, pintor, y su esposa, Mariana Bazán, contraen una obligación con Juan Martínez por un préstamo de dinero, en la que nuevamente intervienen como testigos Damián Adán, moledor de color; Jácome Vautres, arquero de Su Majestad y Juan Bazán, escribano del rey: AHPM, Prot. 5.065, fols. 202r.-203v. 
de febrero de 1621, Carduchi firmaba el finiquito de una deuda con el mercader Juan de Carrión ${ }^{24}$ o el 21 de abril de ese mismo año, se obligaba a pagar una deuda de 208 reales al mercader de hierro Juan de Ibarra en concepto del alquiler del cuarto de su casa (135 reales) y de la cera que se había llevado de su tienda ( 73 reales $)^{25}$, por citar algunos ejemplos. En otras ocasiones, Carduchi intervino como testigo en transacciones como la que tuvo lugar el 22 de septiembre de 1622, cuando se otorgó un poder a Pedro de Isasi para que reclamara y recibiera en nombre de su prima María de Isasi, una serie de piezas de mobiliario, ropa de casa y dos retablos, uno de San Francisco y otro de Nuestra Señora del Rosario ${ }^{26}$. Si bien ha sido posible documentar la asidua participación de Luis Carduchi en este tipo de negocios; por el contrario, no se han hallado evidencias de que se le realizaran encargos artísticos, como sería lógico suponer en alguien que constantemente afirmaba ser pintor. Con todo, las ocupaciones y transacciones de Luis Carduchi durante los primeros años de la década de 1620 traen a la memoria el papel ejercido por su padre -más allá de su labor como pintor stricto sensu-como marchante de arte $^{27}$. Cabe preguntarse, por tanto, si tal vez tras la muerte de Bartolomé Carducho, su hijo Luis pudo haber heredado asimismo la red clientelar de su progenitor y seguir su estela compaginando su labor como pintor con la de comerciante de obras de arte.

Esta vinculación de Luis Carduchi con personalidades del ambiente artístico y cortesano no se circunscribió únicamente a los primeros años de su andadura profesional como pintor, sino que fue una constante a lo largo de su vida cuando, décadas después, su ocupación era la de matemático. En este sentido, resulta interesante referir su intervención en la polémica suscitada por la publicación de la primera parte del tratado de fray Lorenzo de San Nicolás, Arte y vso de Architectvra (1639). La salida al mercado de este tratado fue duramente criticada por el maestro de obras Pedro de la Peña quien presentó una serie de objeciones ante el Consejo Real. En palabras del propio fray Lorenzo, De la Peña "pretendía no solo obscurecer el nombre del Autor, sino que se quemase el libro" 28 . El asunto "hizo mucho ruido en esta Corte" y la obra

24 Finiquito entre Luis Carduchi y Juan de Carrión mercader, Madrid, 21 de febrero de 1621, AHPM, Prot. 5.520, fols. $1 \mathrm{r}-\mathrm{v}$.

25 Obligación de Luis Carduchi en favor de Juan de Ibarra, mercader de hierro, Madrid, 21 de abril de 1621, AHPM, Prot. 5.520, fols. 5r.-v.

26 Poder otorgado por María Isasi, mujer de Juan Bautista Barrantes, a su primo, Pedro Isasi, Madrid, 21 de septiembre de 1622, AHPM, Prot. 5.520, fols. 25r.-25v.

27 F. Baldinucci fue el primero en dar noticia de la actividad desarrollada por Bartolomé Carducho como marchante de pinturas: Baldinucci, F.: Notizie dei professori del disegno da Cimabue in qua, vol. 3, Florencia, Per V. Batelli e Compagni, 1846, pp. 475-476. Posteriormente, analizan esta faceta del pintor florentino: Angulo Íñiguez, D. y Pérez Sánchez, A. E.: Historia de la pintura española. Escuela madrileña del primer tercio del siglo XVII, Madrid, Instituto Diego Velázquez, 1969, pp. 15-19; Lapuerta Montoya, op. cit. (nota 5), pp. 262274 y Lapuerta Montoya, M.: "Bartolomé Carducho y Juan de Bolonia: arte y diplomacia en la corte de Felipe III", Anales de Historia del Arte, 7 (1997), pp. 157-182.

28 San Nicolás, Fray L. de: Segunda parte del arte y vso de architectvra. Dedicada al desamparo que padecio mi redemptor Iesvchristo las tres oras que estuvo viuo enclavado en el Arbol de la Cruz. Con el Qvinto y Septimo libros de Euclides traducidos de latin en Romance y las medidas dificiles de Bonedas y de las superficies y pies cubidos de Pichinas. Con las ordenanzas de la Imperial Ciudad de Toledo aprobadas y confirmadas por la Cesarea Mag. ${ }^{d}$ del S.r Emperador Carlos V. de Gloriosa memoria [...] 1663 [1665], p. 2. La polémica suscitada por la publicación de la primera parte del tratado es referida por: Llaguno y Amírola, op. cit. (nota 6), p. 23; Bonet Correa, A.: "Fray Lorenzo de San Nicolás (1595-1679), arquitecto, tratadista, agustino recoleto", en Bonet Correa, A.: Figuras, modelos e imágenes en los tratadistas españoles, Madrid, Alianza Editorial, 1993, pp. 157-158; Díaz Moreno, F.: "Fray Lorenzo de San Nicolás (1593-1679). Precisiones en torno a su biografía y obra escrita", Anales de Historia del Arte, 14 (2004), pp. 161-162. 
del agustino fue defendida por Luis Carduchi - por aquel entonces matemático - y por el arquitecto Martín de Cortayre. Gracias a ello, el Consejo finalmente autorizó la venta del libro, con la condición de que fray Lorenzo respondiera a las críticas vertidas por su detractor; para lo que hubo que esperar a la publicación de la segunda parte de la obra en $1665^{29}$.

En 1643 encontramos a Carduchi implicado, en esta ocasión, en el contrato para ejecutar un retablo para la iglesia de la villa de Barajas de Huete, concertado por Salvador Muñoz y Gabriel Vázquez, "maestros de escultura y ensamblaxe"30. En él, Luis Carduchi, quien como se ha señalado ya hacía años había dejado de figurar en la documentación como "pintor" y por aquel entonces declaraba ser "matemático de $\mathrm{Su}$ Majestad", hacía las veces de fiador. Muñoz y Vázquez se comprometían a realizar el retablo conforme a la traza que ambos habían entregado al cura y al mayordomo de la iglesia, donde iba "dibuxado todo lo q[ue] se a de haçer de pinçel y escultura" aunque únicamente se les obligaba a realizar "de escultura" cinco de las figuras: San Pedro y San Pablo en los laterales del primer cuerpo, San Juan Bautista en la parte central del segundo cuerpo y San Juan Evangelista y San José, en los laterales del tercero. Además, en el contrato se incluyen una serie de cláusulas sobre la madera y materiales a utilizar y el plazo de un año y medio del que disponían ambos maestros para concluir la obra, desde el momento en que se les pagasen los primeros $500 \mathrm{du}-$ cados para empezar el retablo. Una vez finalizada la obra, esta debería ser examinada por Juan Gómez de Mora y por el padre Bautista de la Compañía de Jesús ${ }^{31}$. La labor de Carduchi en esta empresa también queda recogida en el contrato:

yten ansimismo Es condiçion q[ue] si El d[ic]ho Salbador muñoz antes de aber aCauado El d[ic]ho Retablo faltase a de poder El d[ic]ho Luis carduchi como tal fiador hacerle acauar y En casso q[ue] El d[ic]ho Gabriel Uazquez no prosiga faltando El d[ic]ho Salbador muñoz trauaxando En El d[ic]ho Retrablo El d[ic]ho Gabriel Vazquez Le prosiga y trauaxando En d[ic]ha obra y dexando q[uen]ta a de poder El d[ic]ho Luis Carduchi poner persona q[ue] lo acaue a quien se a de aCudir con las pagas y si hubiere Reçiuido mas cantidad El d[ic]ho Salbador an de ser obligados devolverLo sus herederos y si hubiere Reçiuido menos se les a de aCudir con Ello a los tales herederos ${ }^{32}$.

Parece que a pesar de las cautelas de los comitentes nombrando a un fiador como Carduchi que garantizara la finalización del retablo, la obra debió prolongarse más de lo acordado debido seguramente al fallecimiento de Salvador Muñoz. El escultor otorgó testamento en enero de 1645 y, en una de sus cláusulas, declaraba tener "por mi quenta un retablo para la yglesia de Baraxas de Huete [...] el qual dicho retablo esta hecho muy gran parte y se ba prosiguiendo en él" ${ }^{\prime 3}$. Sin embargo, en 1660 , ya fallecido su fiador, Carduchi, la obra todavía debía permanecer inconclusa. Fue

\footnotetext{
Bonet Correa, op. cit. (nota 28), p. 157.

30 Concierto de Salvador Muñoz y Gabriel Vázquez quienes se obligan a hacer un retablo para la Iglesia de la Villa de Barajas de Huete, siendo fiador Luis Carduchi, matemático de Su Majestad, Madrid, 22 de enero de 1643, AHPM, Prot. 8.407, fols. 66r.-70 v.

Ibidem, fol. $68 \mathrm{r}$.

Ibidem, fols. $69 \mathrm{r} .69 \mathrm{v}$.

Agulló y Cobo, M.: Documentos sobre Escultores, Entalladores y Ensambladores de los siglos XVI al XVIII, Valladolid, Secretariado de Publicaciones de la Universidad de Valladolid, 1978, p. 114.
} 
entonces cuando los herederos de Carduchi otorgaron un poder a Antonio Galiana, geómetra de Su Majestad, para que pudiera:

[...] disponer y ajustar con la persona o personas que les parciere que vn retablo de la Villa de Barajas de Huete, que quedo en poder del dicho don Luis Carduchi, difunto, como fiador de los maestros que le tenían, le pueda acomodar y ajustar en la cantidad [...] de maravedís que le pareçiere con la persona o personas maestros ensanbladores del arte que le quisieren acabar por su quenta y riesgo sacando de la fianza que tiene hecha el dicho Don Luis Carduchi y dándole por libre de ella $[\ldots]^{34}$.

En el estado actual de los conocimientos, resulta difícil determinar el tipo de relación que existía entre los escultores y ensambladores, Salvador Muñoz y Gabriel Vázquez, y Luis Carduchi. Del primero de los artífices hay que destacar que se declaraba arquitecto, retablista, tallista o carpintero, mostrando preferencia por asumir la primera de tales denominaciones ${ }^{35}$. De la importancia que concedía Muñoz al dibujo como el elemento más importante de la arquitectura da cuenta en su manuscrito Libro de Prespectiba de barios Autores con barias Reglas y curiosidades y juguettes particulares $^{36}$. Tal vez en esa concepción del dibujo como herramienta y fundamento científico de las artes que postulaba Muñoz en su tratado podríamos hallar el nexo de unión con Carduchi, aunque no se ha podido documentar otro tipo de contacto entre ambos, más allá del citado contrato de 1643 .

Sea como fuere, lo cierto es que esa no fue la única ocasión en que Carduchi actuó como fiador de un escultor. En ese mismo año de 1643, Sebastián Romero Bejarano -autor de un crucificado para la capilla del Santo Cristo del Hospital de Antón Martín $^{37}$ - y Luis Carduchi, como su fiador, se obligaban a pagar ciertas cantidades por el alquiler que adeudaba el escultor ${ }^{38}$.

Como se ha comentado, Luis Carduchi figuró como "pintor" en la documentación aquí analizada durante los primeros años de la década de 1620. En 1627 su ocupación pasó a ser la de "dimensor", llevando a cabo entonces su primera medición sobre el terreno y trazando su correspondiente planimetría. A pesar de que sobre esos primeros años como pintor en Madrid no tenemos constancia de ninguna pintura rubricada por su pincel, lo cierto es que Carduchi mantendría a lo largo de las décadas sucesivas estrecho contacto con los círculos artísticos de la época y, al mismo tiempo, sus primeras planimetrías, como se verá, presentan con bastante frecuencia motivos decorativos y cartouches delicadamente trazados

\footnotetext{
Ibidem, p. 32.

35 Rodríguez G. de Ceballos, A.: "Alonso Cano y el retablo”, en Álvarez Lopera, J. y otros: Figuras e imágenes del Barroco. Estudios sobre el barroco español y sobre la obra de Alonso Cano, Madrid, Argentaria-Visor Ed., 1999, p. 251.

36 Ibidem. Véase también: Marías, F.: “Teoría e historia en el tratado de arquitectura de Salvador Muñoz”, en Madrid en el contexto de lo hispánico desde la época de los descubrimientos, vol. 2, Madrid, Universidad Complutense de Madrid-Departamento de Historia del Arte II, 1992, pp. 1445-1462.

37 En 1634 el Hospital de Antón Martín concertó con el escultor Juan Sánchez Barba la realización de otro Santo Cristo Crucificado, del que se especificaba que debía "ser del mismo tamaño del Santo Christo que oi tiene puesto en dicho Ospital en la capilla intitulada de Santo Christo, que es el que hiço Sabastian de Uexarano, escultor, y tambueno como el [...]": Agulló y Cobo, op. cit. (nota 33), p. 143; Martín González, J. J.: Escultura barroca en España 1600-1700, Madrid, Ediciones Cátedra, 1998, pp. 262-263.

38 Agulló y Cobo, op. cit. (nota 33), p. 139.
} 
a pluma que denotan una particular sensibilidad artística y una escritura pictórica de raigambre italiana.

\section{El ascenso cortesano y la autoconstrucción profesional de Luis Carduchi: dimensor, matemático, juez para medir jurisdicciones de Felipe IV, ingeniero y arquitecto militar}

Los últimos años del decenio de 1620 y la década sucesiva resultan fundamentales para comprender el devenir profesional de Carduchi y su ascenso social en la corte, para lo cual tejió lazos con importantes figuras de la facción olivarista: primero, con el marqués de la Puebla de Obando; después, con el I marqués de Leganés y, finalmente, buscó el favor del mismísimo conde-duque de Olivares. La reconstrucción de estos procesos, a la que se van a dedicar las líneas que siguen, por un lado, permitirá comprender los caminos por los que Carduchi llegó a ocupar un cargo tan relevante como la Cátedra de Matemáticas y Artillería a partir de 1651. Por otro lado, pondrá de manifiesto la delgada línea que, todavía en el siglo XVII, existía entre disciplinas como la pintura, la topografía, las matemáticas, la ingeniería o la arquitectura militar pues todas ellas fueron cultivadas por la figura que aquí nos ocupa y, al entender de Carduchi (y de otros teóricos), su nexo de unión se hallaba en los principios de la geometría euclidiana y en el dibujo.

La primera referencia a la labor desarrollada por Luis Carduchi como agrimensor o topógrafo data de 1627. El 12 de mayo de ese año, Carduchi rubricaba en calidad de "dimensor" una carta de pago por la que recibía una serie de cantidades del marqués de la Puebla de Obando por haber desempeñado las siguientes tareas:

[...] luis carducho dimensor nombrado para medir el lugar de el zangaron [sic] que agora se llama la puebla de obando $\mathrm{v}[\mathrm{e}] \mathrm{z}[\mathrm{in}]^{\circ}$ desta uilla y otorgo que a rreçiuido del s[eñ $]^{\text {or }}$ don fran[cis $]^{\text {co }}$ de auila marques de la puebla eaballero quarenta mill y quinientos $\mathrm{m}[\mathrm{a}] \mathrm{r}[$ avedi]s los quales le a pagado por rraçon de otros tantos que se montaron treynta y seis dias de salari ${ }^{\circ}$ que se ocupo en yda estada y buelta al lugar del zangano a medir su jurid[icci ${ }^{\text {on }}$ que los v[ein $]^{\text {te }}$ y tres dias se ocupo en amojonar medir y açer dilijençias y los trece dias del camino yda y vuelta desta corte a rraçon de mill ciento y $\mathrm{v}[\mathrm{ein}]^{\text {te }} \mathrm{y}$ cinco $\mathrm{m}[\mathrm{a}] \mathrm{r}$ [auedi]s por dia que entrenta rreales que de los quales $\mathrm{d}[\mathrm{ic}]$ hos quarenta mill y quini[en $]^{\text {tos }}-\mathrm{m}$ [arauedi]s se dio por contento pagado y entregado $[\ldots]^{39}$.

Sabemos con certeza que esta medición de la jurisdicción de la Puebla de Obando al servicio de don Francisco Dávila y Guzmán fue el primer trabajo de Carduchi como agrimensor puesto que, unos años más tarde, el propio Carduchi dejó constancia de ello en su opúsculo impreso titulado Como de deven medir las ivrisdiciones, $y$ demas tierras: sus dificultades, y con que instrumentos (1634), dedicado a dicho marqués ${ }^{40}$. Al comienzo de la obra, Carduchi afirma que la finalidad de su peque-

Carta de pago a Luis Carduchi, Madrid, 12 de mayo de 1627, AHPM, Prot. 5.520, fol. 164r.

40 Carducho, L.: Como se deven medir las ivrisdiciones, y demas tierras: sus dificultades, y con que instrumentos. Al señor don Francisco de Auila y Guzman, Marques de la Puebla de Ouando, Gouernador en el Real Consejo 
ño tratado es la de poner por escrito "lo q[ue] me ha enseñado casi veinte años la Theorica, y especulación desta parte de Geometria [la de medir jurisdicciones] y de casi ocho años de experiencia, y ocupación que he tenido en muchas jurisdicciones por mandado de su Magestad. Digo pues, que la primera medida que hize fue de V. S. [don Francisco Dávila y Guzmán] en Estremadura [...]"41. Por una parte, la afirmación de Carduchi relativa a sus cerca de veinte años de formación teórica parece coincidir con su declaración como estudiante de la Universidad de Salamanca fechada en 1614 y se haría extensible hasta el momento de la publicación del opúsculo en que, como se verá, debía continuar su formación como discípulo de Julio César Firrufino, Catedrático de Matemáticas y Artillería en la corte. Por otra parte, parece claro que el documento notarial citado unas líneas más arriba se corresponde con el pago a Carduchi por su primera tarea como agrimensor, que dataría de los primeros meses del año 1627, y que se convertiría en una actividad que continuó desempeñando durante las décadas sucesivas de manera prácticamente ininterrumpida.

Las características físicas de este pequeño opúsculo impreso Como de deven medir las ivrisdiciones, de 12 folios de a cuarto, así como el hecho de que solo se conservan escasos ejemplares del mismo en la actualidad ${ }^{42}$, invitan a pensar que la tirada de esta publicación fue reducida y que esta "obrita" pudo haber sido concebida como un libro de presentación que ofrecer a un eventual noble y/o protector; una práctica habitual en la época entre quienes aspiraban a ascender en el "laberinto de corte".

Como se ha comentado, Como se deven medir las ivrisdiciones (1634) estaba dedicado a don Francisco Dávila y Guzmán, marqués de la Puebla de Obando, para quien Carduchi realizó su primer trabajo como agrimensor en 1627, del que no se conserva la planimetría. A tenor de las palabras del propio geómetra en su ofrecimiento al marqués queda patente que don Francisco debió ejercer cierta protección en los años previos a la publicación del opúsculo puesto que "avnque este pequeño don ofrezco a U. S. (no puede, ni aun en parte) satisfazer a la mucha merced que cada dia recibo de sus generosas manos"43.

Don Francisco Dávila y Guzmán, fue $\mathrm{V}$ marqués de Loriana y primero de la Puebla de Obando, caballero de la orden de Alcántara, comendador de las Casas de Toledo en la de Calatrava, mayordomo general de la artillería de España y presidente del Consejo de Hacienda, por lo que debió ser una figura que gozó de cierto status en la corte de Felipe IV $^{44}$. Pero sin duda, el aspecto más interesante y que, muy

de Hazienda. Por Luis Carducho, matemático de Su Magestad, Madrid, En la Imprenta del Reyno, 1634, BNE, $\mathrm{VE} / 45 / 106$.

41 Ibidem, fol. 3v.

42 Se han podido localizar tres ejemplares de esta obra conservados en la Biblioteca Nacional de España (BNE) bajo las siguientes signaturas: 3/50642, R/10818(2) y VE/45/106. Es interesante señalar que el ejemplar correspondiente a la signatura $\mathrm{R} / 10818$ (2) se integra en un volumen que contiene otras obras impresas y que presenta una encuadernación en marroquín rojo sobre cartón con el escudo de armas de don Pedro de Aragón, II marqués consorte de Pobar, quien entre 1629 y 1646 ocupó el cargo de ayo del príncipe Baltasar Carlos y entre 1673 y 1680 fue virrey de Nápoles. La encuadernación del volumen R/10818 (2) presenta unas características análogas a las de otro volumen que asimismo formó parte de la biblioteca del que fuera virrey de Nápoles conservado en la Biblioteca Lázaro Galdiano que contiene las Poesías manuscritas del conde de la Coruña (ca. 1647), catalogada por: Yeves Andrés, J. A.: Encuadernaciones Heráldicas de la Biblioteca Lázaro Galdiano, Madrid, Ollero y Ramos - Fundación Lázaro Galdiano, 2008, pp. 194-195, cat. 114.

43 Carducho, op. cit. (nota 40), s. fol.

44 Garma y Salcedo, F. J.: Theatro Universal de España. Descripcion eclesiástica, y Secular de todos sus Reynos y Provincias, en General, y Particular, vol. 4, Barcelona, Imprenta de Mauro Martí, 1751, p. 99. 
probablemente, Luis Carduchi debió conocer y ponderar como un posible medio de ascenso profesional, estribaba en el parentesco y en la filiación cortesana y familiar del marqués de la Puebla de Obando: don Francisco Dávila y Guzmán era hermano de don Diego Mexía Felípez de Guzmán, I marqués de Leganés, y primo del por aquel entonces todopoderoso don Gaspar de Guzmán, conde-duque de Olivares. Fue justamente gracias a la influencia del valido de Felipe IV como don Francisco pasó a formar parte del Consejo de Hacienda a comienzos del año $1626^{45}$. La pertenencia del marqués de la Puebla de Obando a este Consejo tenía cierta trascendencia en relación con las labores de medición que efectuó Carduchi pues, como declaraba el propio agrimensor en la leyenda de la primera planimetría que se conserva de su mano, esta fue realizada "por Mandado de su Mag[esta]d en Virtud de su Real çedula despachada por los señores Presidente y Oydores de su R[ea]l Consejo de haçienda a pedimiento de la dicha Villa este año de $1627^{\prime \prime 46}$.

Tampoco parece casual el momento en que Carduchi firma la dedicatoria de su tratado sobre Como se deven medir las ivrisdiciones: el año de 1634, que vendría a coincidir con el momento álgido de la trayectoria de don Francisco Dávila y Guzmán ${ }^{47}$. En dicho año, el marqués fue enviado a Portugal en calidad de mayordomo y consejero principal de Margarita de Saboya, duquesa de Mantua, nueva gobernadora de Portugal y que habría de frenar el creciente descontento lusitano para con la corona española ${ }^{48}$. En relación con las aspiraciones de promoción social de Carduchi es interesante notar que la presencia y el papel jugado por don Francisco Dávila en Portugal entre 1634 y 1643 han sido interpretados como una estrategia del propio conde-duque de Olivares consistente en posicionar a una figura cercana a su persona en Lisboa para poder así manejar los negocios de Portugal ${ }^{49}$. De ahí que Carduchi, seguramente consciente de todo el entramado de filiaciones que imperaban en la corte española durante las décadas de 1630-1640, se determinara situar bajo la protección del marqués de la Puebla de Obando su primer tratado impreso, en una maniobra de aproximación a una de aquellas "criaturas" olivaristas. En este sentido, como se verá, la ausencia de la corte del que fuera su primer protector a partir de 1634 no sería óbice para que Carduchi desistiera en sus esfuerzos de ganarse el favor de la facción de Olivares. Más bien al contrario, parece que las miras del topógrafo apuntarían todavía más alto, dedicando sus esfuerzos a ganarse el favor del mismísimo conde-duque.

Las planimetrías ejecutadas por Luis Carduchi a partir de 1627 constituyen una valiosa fuente no solo para conocer su labor como agrimensor en esos años sino también para reconstruir su propia autoconstrucción y proyección profesional ${ }^{50}$. El primer dato interesante a este respecto lo encontramos en su mapa más temprano que

Elliott, J. H: El conde-duque de Olivares. El político en una época de decadencia, Madrid, Mondadori, 1990, p. 292.

46 Planta y dimensión de la Villa de Malaga [Málaga del Fresno] Jurisdiccion que era de la Ciudad de Guadalaxara hecha por Luis Carducho florentin, Madrid, 1627, Biblioteca Nacional de España (BNE), MR/43/175.

47 Pérez Preciado, J. J.: El marqués de Leganés y las artes, Tesis doctoral, Madrid, Universidad Complutense de Madrid, 2010, pp. 71-72.

48 Elliott, op. cit. (nota 45), pp. 578-584; Pérez Preciado, op. cit. (nota 47), pp. 71-72.

49 Pérez Preciado, op. cit. (nota 47), pp. 71-72.

50 D. Buisseret efectúa un resumen de la actividad como topógrafo de Carduchi, refiriendo a algunos de los mapas que realizó; ocho de los cuales se conservan en el AGS y uno de ellos en la BNE: Buisseret, op. cit. (nota 6), pp. 1076-1077. Este autor, a su vez, toma las informaciones biográficas relativas a Luis Carduchi, de la voz correspondiente a esta figura contenida en: Navarro Brotóns, op. cit. (nota 6). 
ha llegado a nuestros días, fechado en 1627. Se trata de la referida "Planta y dimensión de la Villa de Malaga Jurisdicçion que era de la Çiudad de Guadalaxara por Luis Carducho florentin por Mandado de su Mag[esta]d en Virtud de su Real çedula despachada por los señores Presidente y Oydores de su R[ea]l Consejo de haçienda a pedimiento de la dicha Villa este año de $1627^{\prime 51}$ (Fig. 1). Esta leyenda se sitúa en una de las dos tarjas rectangulares decoradas con motivos de inspiración renacentista que se insertan en el mapa, cuya delicada escritura pictórica pone de relieve la habilidad como dibujante de Carduchi (Fig. 2). Del contenido de la citada inscripción del mapa llaman la atención dos aspectos. El primero es que Carduchi no asocia a su nombre ningún cargo u ocupación específicos, lo que parece apuntar a que, todavía en los últimos años de la década de 1620, este tipo de trabajos no implicarían una relación profesional estable con la corte. La segunda cuestión que interesa recalcar es el hecho de que el autor manifieste su condición de "florentino" cuando, hasta donde es sabido, a pesar del origen toscano de su padre y de su tío, Luis habría nacido ya en Madrid, hacia 1596, siendo bautizado en la parroquia de San Sebastián de dicha Vi$11 a^{52}$

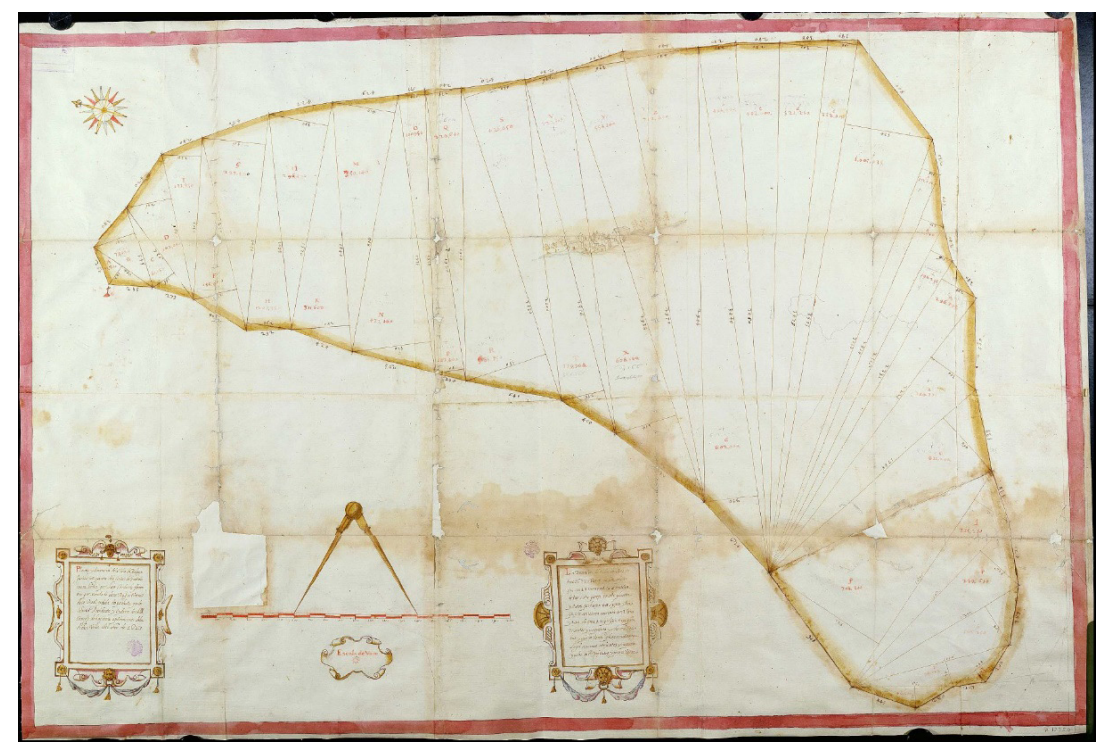

Fig. 1 Luis Carduchi, Planta y dimensión de la Villa de Malaga [Málaga del Fresno] Jurisdicçion que era de la Çiudad de Guadalaxara por Luis Carducho florentin por Mandado de su Mag[esta]d en Virtud de su Real çedula despachada por los señores Presidente y Oydores de su R[ea]l Consejo de haçienda a pedimiento de la dicha Villa este año de 1627, 1627 , dibujo a tinta parda y colores a la aguada sobre papel, Madrid, Biblioteca Nacional de España (BNE), MR/43/175.

51 Planta y dimensión de la Villa de Malaga [Málaga del Fresno] Jurisdiccion que era de la Ciudad de Guadalaxara hecha por Luis Carducho florentin, Madrid, 1627, BNE, MR/43/175.

52 Mazón de la Torre, op. cit. (nota 12), p. 416. 


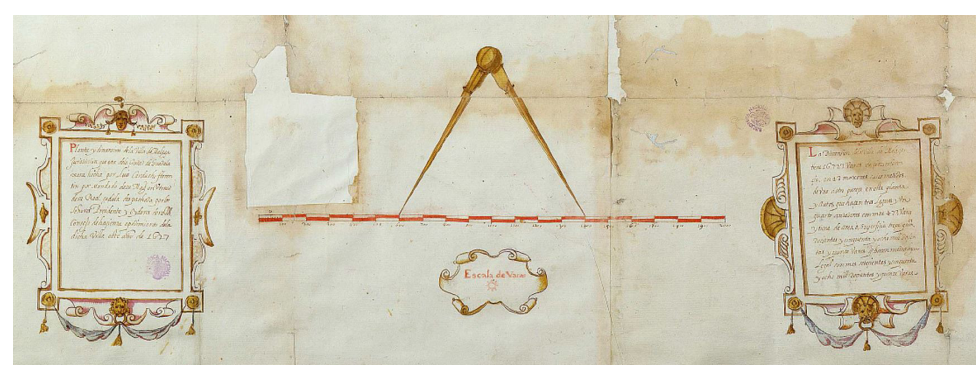

Fig. 2 Luis Carduchi, Detalle de las dos tarjas rectangulares que contienen inscripciones y de la escala de varas presidida por un compás inserta en la Planta y dimensión de la Villa de Malaga [Málaga del Fresno] Jurisdicçion que era de la Çiudad de Guadalaxara por Luis Carducho florentin [...], 1627, dibujo a tinta parda y colores a la aguada sobre papel, Madrid, Biblioteca Nacional de España (BNE), MR/43/175.

Un año más tarde, Luis Carduchi volverá a insistir en su ascendencia toscana en la declaración que se inserta en la siguiente planimetría que se conserva de su mano, en cuyo estilizado cartouche oval decorado por mascarones y sendas figuras femeninas aladas que lo flanquean de tradición renacentista puede leerse lo siguiente: "Dimensión y planta de la Villa de Matalebreras Jurisdiçion q[ue] era de Agreda hecha por Luis Carduchi florentin [...]" $(1628)^{53}$ (Fig. 3). Esta voluntad de dejar constancia en sus obras de su propia autoconsideración en tanto que artífice "florentino" seguramente guarde relación con el hecho de que en la documentación notarial se haga constar de manera ininterrumpida desde su juventud hasta en su propio testamento siempre como "vecino" de la Villa de Madrid y no como "natural" de dicha Villa, como sería más lógico que figurara si, como su partida de bautismo parece apuntar, Luis Carduchi hubiera nacido ya en la capital española.

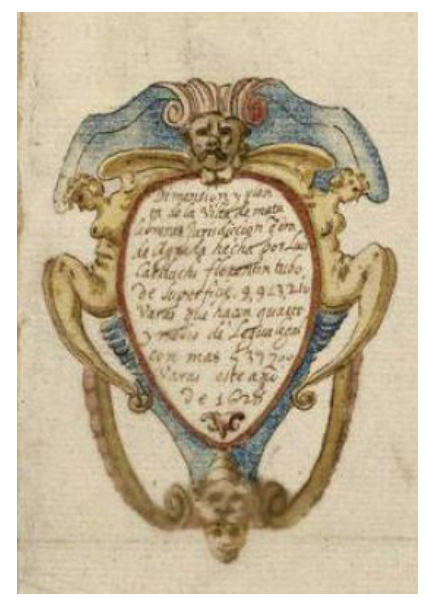

Fig. 3 Luis Carduchi, Detalle del cartouche decorado por mascarones y dos figuras aladas femeninas que flanquean el óvalo que contiene la inscripción de la Planta del término de la Villa de Matalebreras jurisdicción que era de Ágreda con sus medidas, 1628, dibujo a tinta y colores a la aguada sobre papel, Simancas, Archivo General de Simancas (AGS), Mapas, planos y dibujos, 10, 010.

Planta del término de la Villa de Matalebreras jurisdicción que era de Ágreda con sus medidas, Madrid, 30 de abril de 1628, Archivo General de Simancas (AGS), Mapas, planos y dibujos (MPD), 10, 010. 
Si en sus primeros trabajos cartográficos Luis Carduchi quiso recalcar su ascendencia florentina seguramente como aval de prestigio; de un modo análogo, en su publicación más temprana la tradición literaria y científica italiana tiene un peso fundamental. Así, en el referido opúsculo titulado Como se deven medir las ivrisdiciones (1634), las obras de Leon Battista Alberti, Niccolò Tartaglia, Federico Commandino o Cosimo Bartoli constituyen los principales referentes y criterios de autoridad sobre los que se sustenta su discurso. En este sentido, parece que el primogénito de Bartolomé Carducho debió seguir los pasos y la estela de su tío Vicente quien, a pesar de haber llegado a España siendo muy joven acompañando a su hermano mayor, siempre hizo gala de su origen florentino e, incluso, insistiría en su condición de académico por Florencia, como así se autotitularía en la portada de sus Diálogos de la pintura ${ }^{54}$.

Sin embargo, en la leyenda de la siguiente planimetría conservada - fechada en 1631 - desaparecerá la referencia a Florencia y encontraremos ya a un Luis Carduchi que declara ser matemático e ingeniero de Su Majestad. Se trata de la "Planta original del quarto de legua q[u]e su Mag[esta]d vendio al Marques de Truxillos [...] en el termino de Alcala la Real" 55 . En dicho mapa, a pesar de haber eliminado la mención explícita a su ascendencia toscana, puede verse todavía un elemento gráfico que remite a la tradición italiana de la que procedía Carduchi: nos referimos al cartouche que adopta el perfil de un fantástico ser monstruoso entre cuyas fauces se inscribe la leyenda de la planimetría (Fig. 4).

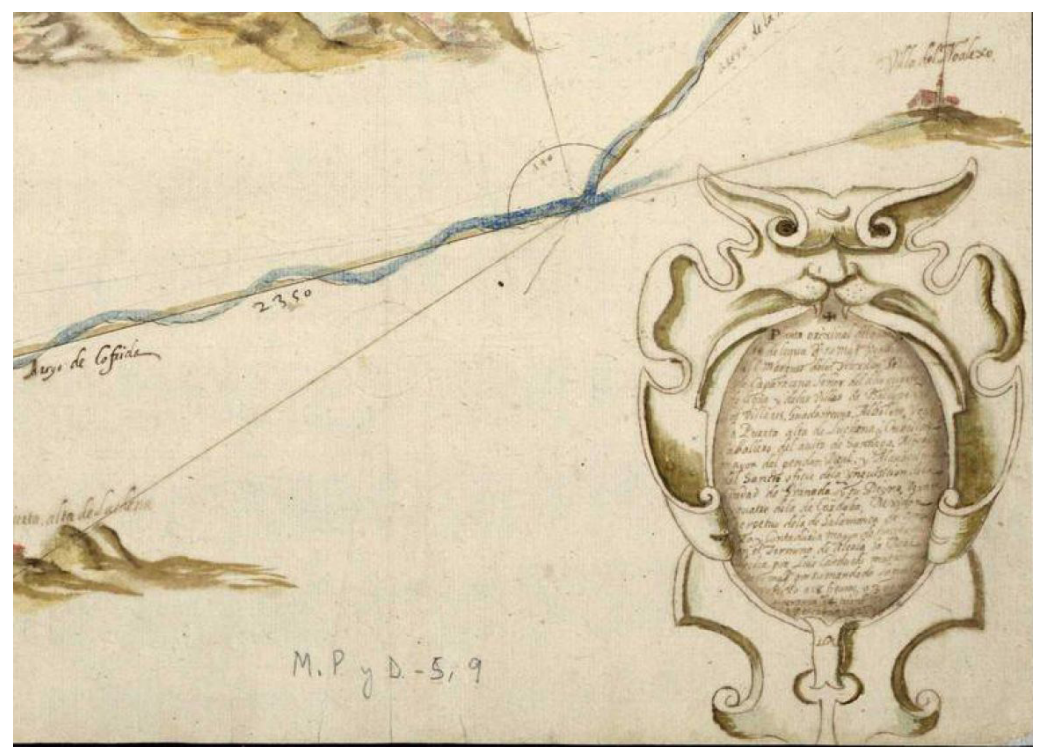

Fig. 4 Luis Carduchi, Detalle del cartouche en forma de ser monstruoso entre cuyas fauces se inserta la inscripción de la Planta original del quarto de legua q[u]e su Mag[esta]d vendio al Marques de los Truxillos señor de Caparacena ... en el termino de Alcala la Real fecha por luis Carduchi matematico de su Mag[esta]d por su mandado, 1631, dibujo a tinta y colores a la aguada, Simancas, Archivo General de Simancas (AGS), Mapas, Planos y Dibujos, 05, 009.

54 Carducho, op. cit. (nota 10), p. 8, nota 7.

55 Planta original del quarto de legua q[u]e su Mag[esta]d vendio al Marques de los Truxillos señor de Caparacena ... en el termino de Alcala la Real fecha por luis Carduchi matematico de su Mag[esta]d por su mandado..., 21 de junio de 1631, AGS, MPD, 05, 009. Este mapa aparece reproducido en: Buisseret, op. cit. (nota 6), p. 1080. 
Así, a partir de 1631 y hasta 1642, Carduchi firmará todos sus mapas declarando ser matemático, si bien no se tiene constancia de que ocupara un cargo institucional en tal calidad. En paralelo a este cambio en su categoría profesional se advierte una tendencia a minimizar los aspectos decorativos de tradición italianizante que poblaban sus primeros mapas, los cuales irán desapareciendo paulatinamente desde comienzos de la década de 1630; una tendencia hacia la simplificación que culminará en la ausencia completa de detalles ornamentales de las planimetrías ejecutadas hacia mediados del decenio de $1650^{56}$.

En relación con esta transición que tiene lugar en la carrera de Luis Carduchi a partir de la década de 1630 y que le conducirá a consolidarse en la corte en tanto que matemático, es interesante traer a colación las conocidas palabras que le dedica su tío Vicente en sus Diálogos de la pintura (1633). La noticia que ofrece el pintor sobre su sobrino Luis ha sido una información repetida por la historiografía ya desde el siglo XIX y que, junto con sus tratados sobre los Elementos geométricos de Euclides y su Chorografia del rio Tajo, han constituido las fuentes principales sobre las que se ha construido la bastante sesgada fortuna crítica de Luis Carduchi hasta la fecha ${ }^{57}$. No obstante, dicha alusión permite introducir nuevos elementos en la trayectoria cortesana que se viene trazando y ponderar el papel de su tío Vicente en el ascenso profesional de Luis.

En su tratado, Vicente Carducho describe la visita que efectuó a casa del I marqués de Leganés, en cuyas cuadras se emplazaba la Academia donde el docto Julio César Firrufino, Catedrático de Matemáticas y Artillería de Su Majestad, leía y enseñaba tales ciencias, teniendo un eminente discípulo que no era otro sino el sobrino del pintor:

Desta escuela tan importante salen cada dia luzidos dicipulos, que favorecidos, y ocupados de su Magestad, harán mucho fruto en la Geografia, Cosmografia, y Astronomia, y serán de grandísima importancia para la navegación y para todo genero de guerras. Y es uno dellos Luis Carduchi, que con los continuos estudios se dispone a que el empleo logre en el grandes cosas en estas ciencias, y las experiencias que del se hazen cada dia, lo prometen. Vimosle en un patio entre culebrinas, y cañones de todos generos, que con algunos Artilleros, y Fundidores reconocia sus metales, cureñas, ñomones, encabalgamientos, balas, cucharas, y los demas pertrechos, con los calibos, y pesos que acostumbraban, y le enseñó su Maestro con tanto fundamento ${ }^{58}$.

Sin duda, la relación entre el Catedrático de Matemáticas y Artillería, Julio César Firrufino, y el pintor Vicente Carducho debió ser muy estrecha pues, no en vano, el

56 Esta tendencia a la eliminación de detalles ornamentales se ve claramente reflejada en las planimetrías ejecutadas por Carduchi en la década de 1650: Planta original de la V[ill]a de Osornillo q[ue] de su Mag[esta]d Compro el Ex[celentisim]o s[eño]r Duq[ue] de pastrana [...], Madrid, 22 de enero de 1653, AGS, MPD, 19, 118; Planta original de la V[ill]a de Padilla de abajo q[ue] de su M[a]g[esta]d Compro el Ex[celentisim]o S[eño]r Duq[ue] de pastrana [...], Madrid, 22 de enero de 1653, AGS, MPD, 19, 117; Planta original de la villa de ornillos Jurisdicion que hera de la Çiudad de Salamanca echa por don Luis Carduchi Catredatico de matematicas y artilleria de Su M[a]g[esta]d que ha comprado el s[eño]r don Rodrigo de Mujica Cau[aller]o de la orden de santiago y encomendado en ella del Cons[ej]o de Su mag[esta]d En el Secreto de milan [...], Madrid, 28 de enero de 1655, AGS, MPD, 62, 80.

57 Para una completa relación de las referencias bibliográficas relativas a Carduchi, véanse las notas 5 y 6.

58 Carducho, op. cit. (nota 10), pp. 418-419. 
propio Firrufino fue el encargado de redactar una encomiástica aprobación de los Diálogos de la pintura y, pocos años después, el pintor nombraría a Firrufino como su testamentario y ejecutor de sus últimas voluntades ${ }^{59}$. Con toda probabilidad, Vicente Carducho debió ser el nexo de unión y la vía por la cual su sobrino, Luis Carduchi, pudo haber pasado a ser discípulo de Firrufino y a asistir a sus lecciones. Pero además, el conocido pasaje recogido por Vicente Carducho en torno a la existencia de una Academia de Matemáticas en casa del marqués de Leganés a la que asistía su sobrino permite atisbar el segundo peldaño en el proceso de ascenso social de Luis: tras haber servido al marqués de la Puebla de Obando, ya entrada la década de 1630 frecuentaba el entorno de un noble relevante, perteneciente a la parentela del conde-duque de Olivares: don Diego Mexía Felípez de Guzmán.

De este modo, sería a lo largo de la década de 1630 cuando el perfil profesional de Luis Carduchi en tanto que matemático se fue afianzando en la corte, aunque es sabido que no llegaría a tener en propiedad la Cátedra de Matemáticas y Artillería hasta que esta no quedara vacante tras el fallecimiento en 1651 de su maestro, Julio César Firrufino ${ }^{60}$.

Del eco que comenzaban a tener los trabajos de Carduchi en la corte alrededor de 1635 nos hablan las informaciones contenidas en una carta fechada a 24 de febrero de dicho año, enviada por el jesuita y Catedrático de Matemáticas en el Colegio Imperial de Madrid, Jean Charles della Faille, a su amigo y cosmógrafo, Michel Florent van Langren, estante en Bruselas ${ }^{61}$. En dicha misiva, el padre Della Faille informa a su corresponsal de la existencia de un mapa ejecutado por Luis Carduchi según la proyección de Mercator ${ }^{62}$ para, a continuación, comentar los distintos sistemas de proyección cartográfica y efectuar una relación de autores que habían escrito sobre loxodromias. Desconocemos el mapa de Carduchi al que se refería el jesuita, pero es significativo que sus trabajos como matemático y cartógrafo fueran conocidos y referidos por una figura como Della Faille, que acabaría siendo nombrado Cosmógrafo Mayor del Consejo de Indias poco tiempo después.

Precisamente, fue otro jesuita vinculado al Colegio Imperial de Madrid -el padre Claudio Richard- quien redactó y firmó la aprobación del tratado publicado por Carduchi en 1637: los Elementos geometricos de Euclides (1637), dedicado al conde-duque de Olivares ${ }^{63}$ (Fig. 5). El frontispicio del tratado-aunque de factura algo

59 Caturla, M. L.: "Documentos en torno a Vicencio Carducho", Arte Español. Revista de la Sociedad España de Amigos del Arte, 26 (1968-1969), p. 172. Sobre Julio César Firrufino, véase: Díaz Moreno, F.: "Teórica y práctica del arte de la guerra en el siglo XVII hispano. Julio César Firrufino y la artillería”, Anales de Historia del Arte, 10 (2000), pp. 169-205. Este autor refiere brevemente a la relación que mantuvieron Firrufino y Vicente Carducho: Ibidem, pp. 179-180.

60 Almirante, op. cit. (nota 6), p. 117; Díaz Moreno, op. cit. (nota 59), p. 194.

${ }_{61}$ Van de Vyver, O.: "Lettres de J.-Ch. della Faille S. I., Cosmographe du Roi à Madrid, à M.-F. van Langren, Cosmographe du Roi à Bruxelles 1634-1645”, Archivum Historicum Societatis Iesu, 46 (1977), pp. 101-103, n 8. Carta de Jean Charles della Faille a Michel Florent van Langren. Madrid, 24 de febrero de 1635. La correspondencia entre ambos pone de manifiesto la amplitud de intereses científicos del matemático jesuita, así como la atención y espíritu crítico con que Della Faille seguía los progresos de diversas materias como las matemáticas, la artillería, la fortificación, la geografía, la cartografía o la física, entre otras, tal y como ha apuntado: Sánchez Martín, F. J.: Método de geometría (1640) de Juan Carlos della Faille. Estudio y edición, Murcia, Editum Signos, 2019, p. 26.

62 La traducción aproximada al español de la expresión utilizada en holandés en esta carta sería la de "grados de longitud creciente". Agradezco a Merlijn Beeftink sus comentarios y apreciaciones acerca de la traducción de esta carta del holandés al español.

63 Carduchi, op. cit. (nota 8). Años más tarde, el propio Claudio Richard publicó un tratado sobre los elementos de Euclides en latín: Ricardvs, C.: Evclidis Elementorvm Geometricorvm Libros Tredecim Isidorvm et Hypsiclem 
tosca- constituye toda una declaración de intenciones por parte de Carduchi. La estructura arquitectónica en la que se inserta el título de la obra, el nombre del destinatario y del autor, aparece presidida por el escudo de armas de don Gaspar de Guzmán situado en la parte central, flanqueado por dos de los sólidos platónicos -un icosaedro y un dodecaedro- a izquierda y derecha, respectivamente. Este preludio gráfico se completaba con las elogiosas palabras que Carduchi dirigía al conde-duque en su dedicatoria, calificando al valido en tanto que protector de las "Sciencias y Artes necesarias a lo político, y militar de las republicas" ${ }^{64}$.

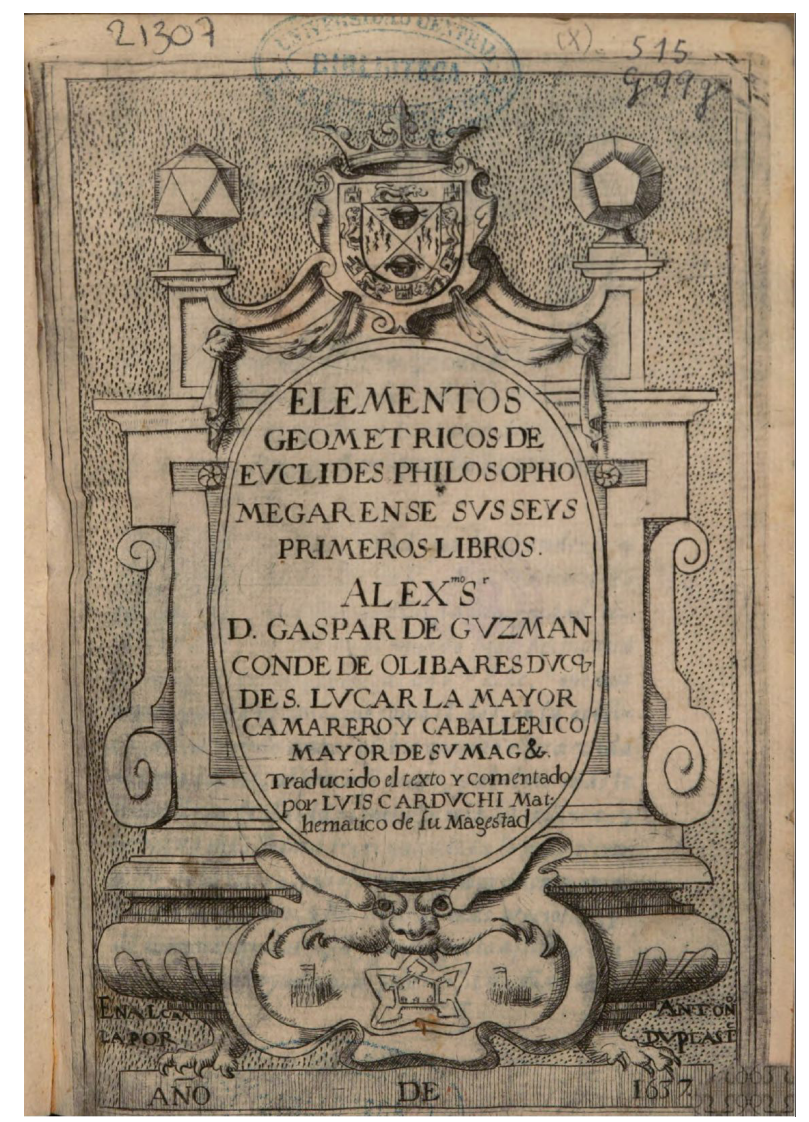

Fig. 5 Luis Carduchi, Elementos geometricos de Evclides philosopho megarense. Svs seys primeros libros. Al Ex[celenetisi]mo S[eño]r D. Gaspar de Gvzman Conde de Olibares dvcq[ue] de S. Lvcar la Mayor camarero y caballeriço mayor de Sv Mag[estad] \& Traducido el texto y comentado por Lvis Cardvchi Mathematico de Su Magestad (frontispicio), Alcalá de Henares, 1637. Nótese cómo la figura monstruosa situada en el centro de la parte inferior de la lápida arquitectónica parece guardar cierta relación con el perfil del cartouche que figuraba en la planimetría de Alcalá la Real (1631) (Fig. 4)

\& Recentiores de Corporibus Regularibus, \& Procli Propositiones Geomtricas [...], Amberes, Ex Officina Hieronymi Verdvsii, 1645. Sobre la labor de jesuitas como Della Faille o Richard en la enseñanzas en materia de matemáticas y fortificación en el Colegio Imperial, véase: De Lucca, D.: Jesuits and Fortifications. The Contribution of the Jesuits to Military Architecture in the Baroque Age, Leiden-Boston, Brill, 2012, pp. 132-164; Sánchez Martín, op. cit. (nota 61), pp. 23-27.

64 Carduchi, op. cit. (nota 8), s. fol. 
No podemos saber con certeza si el tratado de Carduchi llegó, efectivamente, a manos del valido y si pasó a formar parte de su excelsa biblioteca, ya que el registro más completo y estudiado de su librería data de entre 1625 y $1627^{65}$; es decir, es anterior a la publicación de los Elementos geometricos de Evclides (1637). Sin embargo, los datos conocidos en torno a la bibliofilia de don Gaspar de Guzmán apuntan a que el tratado de Carduchi se encontraría dentro de su órbita de intereses ${ }^{66} \mathrm{y}$, además, en uno de los inventarios conocidos de la librería del valido se registran tratados de matemáticas y mecánica de naturaleza afín ${ }^{67}$. Ahora bien, donde sí encontramos registrada la presencia de los Elementos de Carduchi es en la biblioteca de Felipe IV situada en Torre Alta del Alcázar ${ }^{68}$. Teniendo en cuenta que el Índice de dicha librería fue elaborado en 1637 - el mismo año en que se publicó el tratado euclidiano de Carduchi - la incorporación del volumen a la biblioteca del monarca debió ser prácticamente inmediata. Aunque no sabemos si el propio Felipe IV llegaría a leer el libro, seguramente la estrategia de Carduchi de ponerlo al amparo del conde-duque debió contribuir a su difusión en la corte, cumpliéndose así las expectativas que el propio autor dejaba reflejadas al concluir su dedicatoria: "porque lo $\mathrm{q}[\mathrm{ue}]$ podía perder por mio lo grangee, y gane con el Patrocinio de V[uestra] Exc[elencia]"69.

De este modo, Carduchi ponía su trabajo bajo la protección del conde-duque y, a pesar de que la caída del valido estaba cada vez más próxima, parece que el matemático debió continuar gozando en cierto modo del favor del privado de Felipe IV aún en los momentos más difíciles que sucedieron a la crisis de 1640. A este respecto, es sabido del papel crucial del conde-duque en el definitivo impulso del reconocimiento y navegación del río Tajo con fines claramente militares y en el que tomó parte Carduchi, siendo el autor del atlas que lo ilustra de 1641 y que firma en calidad de "yngeniero" $"$.

A la luz de los datos analizados queda patente cómo Luis Carduchi frecuentó el círculo cortesano del valido de Felipe IV y que esta cercanía le debió reportar algunos encargos significativos. Se ha podido documentar un primer contacto en 1627

65 Andrés, G. de: "Historia de la biblioteca del conde-duque de Olivares y descripción de sus códices. I. Formación”, Cuadernos Bibliográficos, 28 (1972), p. 132. Véase también: Andrés, G. de: "Biblioteca Selecta del conde duque D. Gaspar de Guzmán. Segunda parte. Materias”, Cuadernos para la investigación de la literatura hispánica, 21 (1992), pp. 115-142.

66 Roe, J.: "La biblioteca del conde-duque de Olivares y la geografía de la imaginación barroca", en Noble Wood, O., J. Roe, J. y Lawrence, J. (dirs.): Poder y saber. Bibliotecas y bibliofilia en la época del conde-duque de Olivares, Madrid, Centro de Estudios Europa Hispánica, 2011, pp. 261-276.

67 Biblioteca Selecta del Conde Duque de Olivares, D. Gaspar de Guzmán, Real Academia de Historia, Manuscrito 9-5729, fols. 367r.-v. Algunos de los libros que se registran en materia de matemáticas son: "Thesoro magistral de Sciencia Matematica por Gaspar Cardosa de Sequeira en Castellano. M.S. fol. L. 25.", "Las facultades especiales como Geometria. Geografia. Aritmetica. Musica. Astrologia. et. a Ueanse en sus proprios Titulos", “Archimedis Syracusani opera Grecolatina Eustocio Ascalonita interpr. Fol. Cax. 9. N 4", etc. A estos se añaden títulos sobre mecánica de Herón de Alejandría, Jacques Besson o Justo Lipsio, entre otros.

68 Bouza, F.: El libro y el cetro. La Biblioteca de Felipe IV en la Torre Alta del Alcázar de Madrid, Salamanca, Instituto de Historia del Libro y de la Lectura, 2005, p. 111. La obra de Carduchi aparecía registrada en el Índice de los libros en la Torre Alta en el apartado correspondiente a "Matemáticas, Astronomía, Arismética, Geomtría, Prespectiva y Astrología": Ibidem., p. 195 y p. 351.

69 Carduchi, op. cit. (nota 8), s. fol.

70 García Ruipérez, M. y otros (eds.): El Atlas de Carduchi de 1641 para la navegación del río Tajo del Ayuntamiento de Toledo. Estudio introductorio, vol. 1, Toledo, Ayuntamiento de Toledo, 2008, pp. 29-35. Véase asimismo el Anexo VIII. Los memoriales de Eugenio de Salcedo, contenidos en dicha publicación: Ibidem, pp. 47-52. 
con el marqués de la Puebla de Obando, la posterior asistencia de Carduchi en la década de 1630 a la Academia sita en el palacio del marqués de Leganés y, ya hacia finales de ese decenio, el acercamiento al conde-duque de Olivares. Ahora bien, Luis no fue el único de los Carducho que habría mantenido contacto con la Casa de Olivares. En este sentido es interesante recordar que el padre del conde-duque, don Enrique de Guzmán, por aquel entonces embajador español en Roma, participó de manera directa en la contratación de Bartolomé Carducho como ayudante de Federico Zuccaro en 1585 para que se trasladaran desde Italia a trabajar España ${ }^{71}$. Aunque resulta aventurado establecer una correlación causa-efecto entre el contacto de su padre, Bartolomé, con el progenitor del conde-duque, y el posterior vínculo que Luis estableció con algunos miembros de la Casa de Guzmán, no deja de ser significativo apuntar este dato pues pone de relieve cómo la familia Carducho supo trabar lazos y moverse entre los círculos de poder durante los reinados de los tres Felipes.

Por su parte, Felipe IV continuó ocupando a Carduchi en la medición de heredades y jurisdicciones para su servicio en los años sucesivos a la publicación de los Elementos geometricos de Evclides; como así lo atestiguan las planimetrías del término de la villa de Yuncler (Toledo) fechada a 11 de julio de $1637^{72}$ o la de la Atalaya de Cañavete (Cuenca) que data de 14 de julio de 1638 y en cuya leyenda el propio Carduchi da cuenta de cuál fue la motivación que impulsó al monarca a requerir la medición del término, puesto que esta habría sido vendida al marqués de Villena y duque de Escalona y "[.... en la qual medida el d[ic]ho s[eño]r Marq[ue]s pretendio $\mathrm{q}$ [ue] solo se le midiese lo que perteneçia a su M[ajesta]d por deçer q[ue] la maior $\mathrm{p}$ [ar]te del termino era suio de lo qual hiço ynformaçion y mande $\mathrm{q}[\mathrm{ue}]$ despues de aberlo medido se midiese con la d[ic] ha distinción como en los autos consta y en esta Planta lo colorado es lo Realengo q[ue] tubo 13.275.682 varas quadradas y lo verde es del d[ic]ho s[eño]r Marques y tuuo 15.630.500 varas como mas largo consta en la declaración y auto q[ue] con esta Presento [...]"

Pocos meses después de haber trazado dicho plano, Luis Carduchi asistió a la almoneda de bienes de su recientemente fallecido tío - Vicente Carducho - quien, además, le habría nombrado como uno de sus testamentarios. Resultan interesantes las características de los bienes e instrumentos que adquirió en dicha almoneda en diciembre de 1638 pues, a buen seguro, le serían de gran utilidad en el desempeño de las labores como agrimensor y matemático en las que por aquel entonces andaba ocupado. Entre tales objetos cabe destacar que se remataron en Luis Carduchi numerosos volúmenes de trazas, rasguños y dibujos ${ }^{74}$, así como la compra de una gran cantidad de pigmentos

71 Ceán Bermúdez refiere a la venida de Bartolomé “á instancias del embaxador conde de Olivares”: Ceán Bermúdez, J. A.: Diccionario histórico de los más ilustres profesores de las Bellas Artes en España, vol. 1, Madrid, En la Imprenta de la viuda de Ibarra, 1800, pp. 240-241. El contrato firmado en Roma, el 17 de agosto de 1585, entre Federico Zuccaro y don Enrique de Guzmán, fue dado a conocer por: Bertolotti, A.: Artisti urbinati in Roma prima del secolo XVIII: notizie de documenti raccolti negli archivi romani, Urbino, E. Righi, 1881, p. 23. Sobre la venida de Bartolomé a España remitimos a: Lapuerta Montoya, op. cit. (nota 5), pp. 237-240 y a la bibliografía citada por la autora. Es interesante notar que en las numerosas peticiones efectuadas a los monarcas tras la muerte de Bartolomé por parte de su viuda, Jerónima Capelo, y de sus hijas, reclamando el pago de las distintas mercedes recibidas en vida por el pintor se alude explícitamente al contrato firmado por Bartolomé en Roma con el conde de Olivares: Ibidem, pp. 243-247.

72 Planta del término de la villa de Yuncler partido de Toledo, Madrid, 11 de julio de 1637, AGS, MPD, $05,003$.

73 Planta orixina [sic] de la Villa del Atalaia Jurisdicçion q[ue] era de la Villa de S. Clemente [...], Madrid, 14 de julio de 1638, AGS, MPD, 05, 002.

74 Caturla, op. cit. (nota 59), p. 213. 
y materiales para dibujar como carmín, pavonazo o ancorza ${ }^{75}$. Además, Luis adquirió un par de instrumentos y libros: concretamente, "dos compases Vno de laton y otro de yerro con abuxeros en veynte y seis R[eale]s", un tratado de Leon Battista Alberti, otro de geometría de Durero, un tratado de arquitectura de Serlio, un ejemplar de perspectiva de Vignola y la Plática manual de artillería de Luis Collado ${ }^{76}$. A estos, se añade la compra por parte de Luis de una serie de pinturas y objetos artísticos entre los que cabe señalar un friso "del Mantegna", "vn leon echado con su moldura", "Vn borroncillo de la Visitacion", "los dos países de Don Diego de Acebedo" y "vn bosquexo de la Concepcion empeçado" "A7 . Así, el elenco de bienes que adquirió el sobrino del difunto pintor pone de manifiesto tanto los intereses científicos de su primer propietario -Vicente- como de su nuevo poseedor -Luis-; al tiempo que reflejan los intereses artísticos del matemático. Estos objetos, por lo tanto, denotan esa convivencia entre arte y ciencia que caracterizó el perfil cultural de la familia Carducho.

Ya entrada la década de 1640, Luis Carduchi dejó constancia en algunos documentos de lo que parece ser un cierto matiz en su condición profesional. Si como se ha comentado hasta aproximadamente 1642 Carduchi se declarará fundamentalmente "matemático", será a partir del año siguiente cuando la categoría profesional que hará constar de manera reiterada en documentos de naturaleza diversa es la de "matemático y arquitecto militar". En este sentido, resulta interesante notar que en 1643 Carduchi solicitó la plaza de maestro mayor del Alcázar de Toledo que habría quedado vacante tras la muerte de Fernández de Salazar. En el memorial presentado por Carduchi para solicitar dicha plaza declaraba que su profesión era la de matemático y arquitecto militar. El encargado de dar su parecer sobre los candidatos fue Juan Gómez de Mora quien otorgó finalmente el puesto a Felipe Lázaro de Goiti, quedando en el segundo y tercer lugar, Luis Carduchi y Alonso Cano, respectivamente ${ }^{78}$.

Cinco años más tarde, Carduchi firmaba las "Plantas orijinales de las Villas de Yebes y Baldarachas q[ue] de su Mag[esta]d ha comprado el s[eño]r Conde Ju[an] esteban ymbrea" haciendo constar que su categoría profesional era asimismo en 1648 la de "Mathematico y Architeto militar de su M[agesta]d" ". En el estado actual de la investigación sobre Cardcuhi no se conocen con precisión cuáles debieron ser los trabajos concretos que pudo desempeñar como arquitecto militar. Sin embargo, pronto dejó de recibir tal consideración, al postularse como Catedrático de Matemáticas y Artillería.

\section{El zénit. Luis Carduchi, Catedrático de Matemáticas y Artillería del Consejo de Guerra}

A comienzos del mes de julio de 1650 Luis Carduchi solicitó al Consejo de Guerra sustituir a Julio César Firrufino, por aquel entonces enfermo, en su labor al frente de

\footnotetext{
Ibidem.

Ibidem.

Ibidem.

Martín González, J. J.: “Arte y artistas del siglo XVII en la Corte”, Archivo Español de Arte, 31-122 (1958), pp. 127-128.

79 Plantas orijinales de las Villas de Yebes y Baldarachas q[ue] de su Mag[esta]d ha comprado el s[eño]r Conde $\mathrm{Ju}[\mathrm{an}]$ Esteban ymbrea hechas por Luis Carduchi Mathematico y Architetto militar de su M[a]g[esta]d y su Juez para susod[ic] ho, Madrid, 21 de noviembre de 1648, AGS, MPD, 17, 52.
} 
la Cátedra de Matemáticas y Artillería ${ }^{80}$. En dicho memorial, Carduchi detallaba las credenciales que le capacitaban para ocupar un puesto de esas características. Nuevamente, se presenta ante los miembros de la Junta de Guerra en calidad de matemático, arquitecto militar y uno de los jueces nombrados para medir jurisdicciones; una labor esta última en la que llevaba sirviendo veintitrés años. Además, añade que llevó a cabo el reconocimiento del Río Tajo "para hacerle navegable hasta Lisboa, y ajusto su disposición que se hubiera executado a no faltar medios para ello"81. A estas labores, Carduchi incorpora su faceta como teórico indicando que había escrito doce libros en materia de matemáticas, de los cuales solo había podido publicar uno y que tendría intención de dar a la estampa los once restantes justificando su impresión en "la utilidad de los naturales, y servicio de V[uestra] M[ajesta]d por ser en Ydioma Castellano" Con tal afirmación, Carduchi debía referirse como su único tratado impreso a los Elementos geometricos de Evclides (1637), si bien se desconoce cuáles podrían ser los restantes libros sobre la disciplina que redactó. Por último, añade que tenía en su casa una escuela donde enseñaba geometría, fortificación y artillería.

En su respuesta a la solicitud, la Junta de Guerra, encabezada por el marqués de Aguilafuente, consideró a Carduchi como un "subjeto aproposito para la ocupaçion", señalando la relevancia que revestía que hubiera quien enseñase en dicha Cátedra por la falta de personas prácticas en la materia. De este modo, Carduchi asumía las obligaciones de leer geometría, fortificación y artillería en casa del Capitán General de la Artillería pero no podría gozar del sueldo mientras viviera Julio César. Solo en caso de que Firrufino falleciera y Carduchi le sobreviviera, podría acceder a la plaza con un sueldo de 25 escudos de los 50 que cobraba su predecesor. Los 25 escudos restantes los recibía la hija de Julio César, llamada Catalina y, si esta muriese, pasarían a engrosar la nómina de Carduchi.

El 24 de julio de ese mismo año el Consejo de Guerra elevó la decisión al rey Felipe IV. En esa consulta al monarca se incluyen una serie de informaciones interesantes. Aunque se vuelve a insistir en la falta de personas entendidas en artillería y fortificación en los ejércitos, se añaden una serie de matices significativos:

Habiéndose visto en el Consejo; siente, que por la poca practica y inteligencia que los naturales tienen de esta profesión en los Egercitos, es mas ordinario valerse de Estrangeros para las cosas necesarias de este genero, por ser en el mas inteligentes, y siendo tan del servicio de Vuestra Magestad que se habiliten personas naturales en este ejercicio; es de parecer el Consejo, conuiene mucho que haya quien lea esta Catedra, y que se señalase alguna pieza en Palacio para ello, como se hizo por lo pasado, porque se hiciese con mas decoro, con lo cual no solo acudirían los soldados á oir hallándose á la mano cuando acuden a sus pretensiones, empleando el tiempo en ocupación tan licita, y del servicio de Vuestra Magestad, sino también otras personas particulares, que sin ocupación por ociosidad acuden á los patios, de que se podria sacar mucho fruto $[\ldots]^{83}$.

80 Consulta de la Junta de Guerra de España que representa a V. M. combendrá q[ue] Luis Carduchi lea la Cathedra de Artillería en lugar de Julio Çesar Ferrufino, Madrid, 5 de julio de 1650, AGS, Guerra y Marina, Leg. 1.754. Existe copia de este documento en: Archivo Histórico Militar (AHM), Col. Aparici, Sign. 1-3-16, fol. 23r.-24v. 81 Ibidem.

82 Ibidem.

83 Consulta del Consejo de Guerra a Su Majestad, sobre la pretensión que hizo Luis Carduchi matemático y arquitecto militar de sustituir la Cátedra de Artillería que tiene Julio César Ferrufino, Madrid, 24 de julio de 1650, AHM, Col. Aparici, Sign. 1-3-16, fol. 25r.-26r. 
La carencia de especialistas en artillería "naturales de estos reinos" y la dependencia de expertos extranjeros, formaba parte de una polémica que se remontaba a finales de siglo XVI pero que continuaba plenamente candente. Ya en 1594, Pedro López de Soto, veedor y contador de la Armada de Lisboa, denunciaba esta problemática en un memorial dirigido al rey Felipe II $^{84}$. Tan solo cuatro años más tarde, el protomédico Cristóbal Pérez de Herrera se hacía eco de la necesidad de este tipo de profesionales, al tiempo que señalaba las consecuencias que ello implicaba: además del elevado coste que suponía para las arcas de la corona, la condición de extranjeros y vasallos de otros monarcas de este tipo de técnicos cuyas labores revestían gran importancia estratégica para la defensa del reino, suponía un riesgo y las sospechas de falta de fidelidad al rey de España a menudo planearon sobre ellos $^{85}$. De este modo, todavía en 1650 España continuaba arrastrando esas mismas carencias.

La segunda cuestión interesante que emerge de la consulta del Consejo de Guerra anteriormente reproducida reside en la referencia al lugar donde se desarrollarían las lecciones de Carduchi como Catedrático de Matemáticas y Artillería. Si con anterioridad, se sabe que Julio César Firrufino las había impartido en casa del Capitán General de la Artillería de quien dependía la Cátedra desde su creación; ahora Carduchi debería hacerlo en alguna de las estancias del Alcázar de Madrid. En opinión del Consejo de Guerra, este cambio de ubicación atraería a diversos y potenciales públicos: los soldados que frecuentaban el palacio para resolver sus asuntos en los Consejos ${ }^{86}$, así como aquella gente ociosa que habitualmente paseaba por los patios del Alcázar; unos espacios donde se disponían tiendas en las que adquirir mercancías diversas y donde a menudo se congregaba un gran concurso de gente ${ }^{87}$.

Si bien Carduchi fue ratificado como sustituto de Firrufino en el verano de 1650, sus lecciones no debieron ni comenzar de inmediato ni estar exentas de problemas. El 19 de noviembre, el marqués de Aguilafuente daba aviso de que a Luis Carduchi hacía días que se le habían señalado las "piezas en Palacio para leer Matematicas [...] y deja de hacerlo por no tener asientos ni Bufetes" ${ }^{88}$. El marqués, con el apoyo de la Junta de Guerra, argumentaba que en las arcas "no hay un Real con que poder acudir a nada" y pedía que se diera orden a la furriera de palacio para que propor-

84 García Tapia, N. y Vicente Maroto, M. I.: "Las escuelas de artillería y otras instituciones técnicas", en López Piñero, J. M. (dir.): Historia de la ciencia y de la técnica en la Corona de Castilla. Siglos XVI y XVII, vol. III, Salamanca, Junta de Castilla y León-Consejería de Educación y Cultura, 2002, pp. 77-78.

85 Pérez de Herrera, C.: Discursos del Amparo de los legitimos pobres; y reducción de los fingidos: y de la fundación y principio de los Albergues destos Reynos, y amparo de la milicia dellos, Madrid, Por Luis Sánchez, 1598, fols. $57 \mathrm{r} .-58 \mathrm{v}$.

86 Desde finales del siglo XVI, la presencia de soldados en la corte madrileña aumentó considerablemente, dando lugar a problemas de orden público. Algunas noticias sobre la cuestión se encuentran en: Castro Isabeta, F. J.: "Mentidero de Madrid: la corte como comedia", en Castillo Gómez, A. y Amelang, J. S. (dirs.), Opinión pública y espacio urbano en la Edad Moderna, Gijón, Ediciones Trea, 2010, pp. 46-48.

87 Existen diversos testimonios y relatos del ambiente que se vivía en las tiendas situadas en el patio del Alcázar. Particularmente sugerente es el retrato que de ese ambiente ofrece un criado del conde Alaguas durante su declaración en un proceso inquisitorial en 1624, en el que narra la conservación mantenida al hilo de un mapa de la ciudad de Argel que se vendía en una de las tiendas del Alcázar: Molina Campuzano, M.: Planos de Madrid de los siglos XVII y XVIII, Madrid, Ministerio de Administraciones Públicas, pp. 225-226, nota b.

88 Consulta de la Junta de Guerra de España sobre que de la furriela se den los bufetes y bancos necesarios para que en la pieza que se ha señalado en Palacio se lea la Cátedra de Artillería y Matemáticas, Madrid, 19 de noviembre de 1650, AHM, Col. Aparici, Sign. 1-3-16, fol. 27r.-v. 
cionara el mobiliario requerido "pues esto es cosa de tan poca consideración, y el beneficio que siguirá será grande" 89 .

Sobre la actividad docente de Carduchi al frente de la Cátedra son pocas las noticias de las que se disponen. Un decreto de 1 de diciembre de 1656 emitido por Felipe IV y dirigido a don Luis de Haro ofrece algunas informaciones al respecto ${ }^{90}$. En él se especifica que por indicación del Consejo de Guerra debido a "la falta Grande" de ingenieros que hay en el reino y la conveniencia del servicio de Luis Carduchi como Catedrático de Matemáticas, se le ordena que las lea hora y media al día por la mañana en el Hospital de los Desamparados "para q[ue] se Ynstruyan en este exerzizio y Profess[i]on los muchachos que se Ynclinaren a ella" y otra hora y media por la tarde en palacio. Para tales lecciones se añade que deberá proveerse lo necesario, los bancos que fueren menester y una pieza de artillería de bronce pequeña de la Real Armería.

Así, Luis Carduchi ocupó la Cátedra de Matemáticas y Artillería desde 1651 hasta el momento de su muerte acaecida en 1657. Al mismo tiempo, continuó midiendo jurisdicciones al servicio de la corona. En sus postreras voluntades, otorgadas el 23 de febrero de 1657, quedan registradas las cantidades que se le adeudaban por ambas ocupaciones: se le debían aproximadamente 10.000 reales del sueldo que se la pagaba cada mes por asistir a la Cátedra de Matemáticas, mientras que el marqués de Fuente el Sol tenía pendiente abonarle 150 ducados por su labor en la medición del término que había comprado al rey Felipe IV $^{91}$.

Además, en su testamento Carduchi ordenaba a sus albaceas que para hacer frente al pago de las mandas y legados recogidos en sus últimas voluntades vendieran todos sus bienes (en pública almoneda o "fuera de ella"), con una excepción: tanto su casa como "lo que estuviere y pareçiere dentro del apossento donde yo tengo mi Scritorio todo ello que son Libros de mi facultad ynstrumentos y todas las demas alajas que en el estan de la puerta adentro" los legaba a su última esposa ${ }^{92}$.

Con todo, la documentación aquí estudiada ha permitido reconstruir la interesante trayectoria vital y profesional de Luis Carduchi, cuya evolución y ascenso social estuvieron marcados por los vínculos que estableció tanto con los círculos artísticos como, sobre todo, con los círculos de poder cortesanos de quienes emanaban los encargos y mercedes. Las estrategias de promoción social desplegadas por Carduchi no fueron un caso aislado en las cortes de la Europa de la época; más bien al contrario. A día de hoy, la interpretación del fulgurante cursus honorum de figuras coetáneas a Luis Carduchi como el pintor Diego Velázquez o el filósofo Galileo Galilei está indisolublemente ligada a los servicios que prestaron y a los cargos que ocuparon en las cortes española y florentina, respectivamente ${ }^{93}$. La cultura de corte fue, por tanto,

\footnotetext{
Ibidem.

90 Real decreto para que Luis Carduchi Catedrático de Matemáticas las lea hora y media al día por la mañana en el Hospital de los Desamparados, Madrid, 12 de diciembre de 1656, Archivo General de Palacio (AGP), Sección Histórica, Armería Real, Caja 308/17. Agradezco al Dr. Antonio Urquízar Herrera que me señalara la existencia de este documento.

91 Testamento de Luis Carduchi, Madrid, 23 de febrero de 1657, AHMP, Prot. 6.681, fols. 920r.-923v.

92 Ibidem, fol. $921 \mathrm{v}$.

93 Entre los numerosos estudios que han puesto el foco en la faceta cortesana de Velázquez y en la interpretación de su obra en el marco de esa cultura de corte, señalamos aquí solo algunos de los más destacados son: Brown, J.: Velázquez, pintor y cortesano, Madrid, Alianza Editorial, 1986; Brown, J.: Velázquez, Rubens y Van Dyck: pintores cortesanos del siglo XVII, Madrid, Museo Nacional del Prado - Ediciones El Viso, 1999; Portús Pérez, J. (ed.):Velázquez y la familia de Felipe IV, Madrid, Museo Nacional del Prado, 2013. En cuanto al estudio de
} 
el ámbito fundamental en la promoción tanto del arte como de la ciencia en la Europa del Antiguo Régimen. En el caso de Luis Carduchi, el análisis aquí realizado en torno a sus vínculos con los círculos de poder y de los nobles del entorno del conde-duque de Olivares, ha permitido identificar con mayor precisión cuáles fueron las estrategias que urdió y las redes de promoción social que tejió, al tiempo que reconstruir cómo se desarrolló su ascenso y autoconstrucción profesional hasta llegar a ocupar la Cátedra de Matemáticas y Artillería.

Además, se ha demostrado cómo Carduchi, a lo largo de su carrera, tuvo ocupaciones como la de pintor, agrimensor - una categoría especializada en el ámbito de la cartografía escasamente conocida en la España de la época ${ }^{94}$, , juez para medir jurisdicciones, matemático, ingeniero y arquitecto militar. Tal vez, el cultivo de disciplinas a priori tan dispares a ojos de la historiografía moderna haya podido ser la causa que explique las "fragmentarias" aproximaciones que se han efectuado a la figura de Carduchi, al no encontrar un encaje plenamente satisfactorio en las modernas acepciones de artes y ciencias, herederas de las divisiones que se fraguaron en el siglo XVIII. En este sentido, el hecho de que un solo individuo declarara ocuparse de las referidas disciplinas invita a reflexionar y a interpretar trayectorias como la de Carduchi dejando de lado la aplicación de conceptos propios del sistema moderno de las artes (o bellas artes) -y también de las ciencias- que se impusieron en fecha posterior y que pueden resultar distorsionadoras a la hora de analizar la vida y la producción de "artistas" y "científicos" que vivieron en los siglos precedentes ${ }^{95}$. A este respecto, es interesante recordar que el estudio de las matemáticas aplicadas, la arquitectura, la fortificación y las artes visuales formaba parte del programa pedagógico de instituciones como la florentina Accademia del disegno, fundada en $1563^{96}$. En ella, impartió lecciones de matemáticas y perspectiva Ostilio Ricci, experto en dicha materia y en ingeniería militar, quien fue profesor de cortesanos, pintores, escultores y arquitectos, pero también de figuras como el propio Galileo durante sus primeros años en Florencia ${ }^{97}$. En consecuencia, todas las materias cultivadas por Luis Carduchi constituían distintas caras de un mismo prisma que se integraban y resultaban perfectamente coherentes con la tradición cultural heredera del Renacimiento italiano - y, más específicamente, toscano - que defendieron y ejercitaron tanto su padre como su tío. Resulta ilustrativo para concluir contraponer las ideas postuladas por Vicente Carducho y las de Luis Carduchi, procedentes de un tratado en defensa de la liberalidad de la pintura y de un escrito sobre geometría aplicada, respectivamente. Así, en los Diálogos de la pintura Vicente Carducho abogaba por la conjunción de las definiciones de ciencia y arte en su defensa de la nobleza de la pintura:

la trayectoria de Galileo y su autoconstrucción profesional en el contexto cortesano, cabe citar a: Westfall, R.: "Science and patronage: Galileo and the telescope", Isis 76 (1985), pp. 11-33; Biagioli, M.: Galileo cortesano. La práctica de la ciencia en la cultura del absolutismo, Buenos Aires, Katz Editores, 2008.

94 Buisseret, op. cit. (nota 6), p. 1076.

95 Las palabras "artista" y "científico" aparecen entrecomilladas de manera intencionada en este pasaje pues se trata de dos términos que rara vez se utilizaron durante los siglos XVI y XVII y, por lo tanto, su empleo por parte de la historiografía para referirse a los artífices del periodo que aquí se estudia constituye -las más de las veces- un anacronismo: Burke, op. cit., (nota 4), p. 53, nota 1.

96 Jack, M. A.: "The Accademia del Disegno in Late Renaissance Florence", The Sixteenth Century Journal, 7/2 (1976), p. 18; Biagioli, op. cit. (nota 93), p. 20.

97 Ibidem. 
Que participe [la pintura] de la nobleza natural, que es la segunda, tampoco ai duda; porque la Ciencia es un conocimiento de la cosa, mediante la causa, por la qual es: que es lo mismo que saber, y poseer con conocimiento cierto, y con razon, la calidad de la cosa que se profesa; y Arte es un habito operativo, que tiene y ha recta razon y orden de las cosas factibles. Que juicio negará que se difundan ambas difiniciones de la docta Pintura ${ }^{98}$.

Por su parte, Luis Carduchi en su tratado de 1634 ofrecería una definición de la geometría en tanto que "ciencia, ò arte, que contempla las formas, ò figuras de la quantidad continua inmobil" ${ }^{\prime 9}$. De este modo, arte y ciencia presentaban definiciones convergentes, como si de dos caras de una misma moneda se tratase.

\section{Bibliografía}

Agulló y Cobo, M.: Documentos sobre Escultores, Entalladores y Ensambladores de los siglos XVI al XVIII, Valladolid, Secretariado de Publicaciones de la Universidad de Valladolid, 1978.

- Documentos para la historia de la pintura española, vol. 1, Madrid, Museo del Prado, 1994.

- Documentos para la historia de la pintura española, vol. 2, Madrid, Museo del Prado, 1996.

Almirante, J.: Bibliografía militar de España, Madrid, Imprenta y Fundición de Manuel Tello, 1876.

Andrés, G. de: "Historia de la biblioteca del conde-duque de Olivares y descripción de sus códices. I. Formación”, Cuadernos Bibliográficos, 28 (1972), pp. 131-142.

— "Biblioteca Selecta del conde duque D. Gaspar de Guzmán. Segunda parte. Materias", Cuadernos para la investigación de la literatura hispánica, 21 (1992), pp. 115-142.

Angulo Íñiguez, D. y Pérez Sánchez, A. E.: Historia de la pintura española. Escuela madrileña del primer tercio del siglo XVII, Madrid, Instituto Diego Velázquez, 1969.

Baldinucci, F.: Notizie dei professori del disegno da Cimabue in qua, vol. 3, Florencia, Per V. Batelli e Compagni, 1846.

Biagioli, M.: Galileo cortesano. La práctica de la ciencia en la cultura del absolutismo, Buenos Aires, Katz Editores, 2008.

Bertolotti, A.: Artisti urbinati in Roma prima del secolo XVIII: notizie de documenti raccolti negli archivi romani, Urbino, E. Righi, 1881.

Bonet Correa, A.: "Fray Lorenzo de San Nicolás (1595-1679), arquitecto, tratadista, agustino recoleto", en Bonet Correa, A.: Figuras, modelos e imágenes en los tratadistas españoles, Madrid, Alianza Editorial, 1993, pp. 157-175.

Bouza, F.: El libro y el cetro. La Biblioteca de Felipe IV en la Torre Alta del Alcázar de Madrid, Salamanca, Instituto de Historia del Libro y de la Lectura, 2005.

Brown, J.: Velázquez, pintor y cortesano, Madrid, Alianza Editorial, 1986.

— Velázquez, Rubens y Van Dyck: pintores cortesanos del siglo XVII, Madrid, Museo Nacional del Prado - Ediciones El Viso, 1999.

Buisseret, D.: "Spanish Peninsular Cartography, 1500-1700", en Woodward, D. (ed.), Cartography in the European Renaissance, vol. 3, part 1, Chicago-Londres, The University of Chicago Press, 2007, pp. 1069-1094.

Carducho, op. cit. (nota 10), pp. 136-137.

99 Carducho, op. cit. (nota 40), fol. 2 r. 
Burke, P.: El Renacimiento italiano. Cultura y sociedad en Italia, Madrid, Alianza, 2001.

Castro Isabeta, F. J.: "Mentidero de Madrid: la corte como comedia", en Castillo Gómez, A. y Amelang, J. S. (dirs.), Opinión pública y espacio urbano en la Edad Moderna, Gijón, Ediciones Trea, 2010, pp. 43-58.

Carduchi, L.: Elementos geometricos de Evclides philosopho megarense. Svs seys primeros libros. Al Ex[celenetisi]mo S[eño]r D. Gaspar de Gvzman Conde de Olibares dvcq[ue] de S. Lvcar la Mayor camarero y caballeriço mayor de Sv Mag[estad] \& Traducido el texto y comentado por Lvis Cardvchi Mathematico de Su Magestad, Alcalá de Henares, Por Antonio Duplast, 1637.

Carducho, L.: Como se deven medir las ivrisdiciones, y demas tierras: sus dificultades, y con que instrumentos. Al señor don Francisco de Auila y Guzman, Marques de la Puebla de Ouando, Gouernador en el Real Consejo de Hazienda. Por Luis Carducho, matemático de Su Magestad, Madrid, En la Imprenta del Reyno, 1634, BNE, VE/45/106.

- Chorografia del rio Tajo: año de 1641, 2 vols., Toledo, Ayuntamiento de Toledo, 2008.

Carducho, V.: Diálogos de la Pintura. Su defensa, origen, esencia, definición, modos y diferencias. Edición, prólogo y notas de Francisco Calvo Serraller, Madrid, Ediciones Turner, 1979.

Caturla, M. L.: "Documentos en torno a Vicencio Carducho", Arte Español. Revista de la Sociedad España de Amigos del Arte, 26 (1968-1969), pp. 145-221.

Ceán Bermúdez, J. A.: Diccionario histórico de los más ilustres profesores de las Bellas Artes en España, vol. 1, Madrid, En la Imprenta de la viuda de Ibarra, 1800.

De Lucca, D.: Jesuits and Fortifications. The Contribution of the Jesuits to Military Architecture in the Baroque Age, Leiden-Boston, Brill, 2012.

Díaz Moreno, F.: "Teórica y práctica del arte de la guerra en el siglo XVII hispano. Julio César Firrufino y la artillería", Anales de Historia del Arte, 10 (2000), pp. 169-205.

— "Fray Lorenzo de San Nicolás (1593-1679). Precisiones en torno a su biografía y obra escrita", Anales de Historia del Arte, 14 (2004), pp. 157-179.

Elliott, J. H: El conde-duque de Olivares. El político en una época de decadencia, Madrid, Mondadori, 1990.

Esteban Piñeiro, M.: “Carduchi, Luis”, en Silva Suárez, M. (ed.): Técnica e ingeniería en España. El Renacimiento. De la técnica imperial y la popular, vol. 1, Zaragoza, Real Academia de Ingeniería-Institución "Fernando el Católico"-Prensas Universitarias de Zaragoza, 2008.

Gállego, J.: El pintor de artesano a artista, Granada, Universidad de Granada, 1976.

García Ruipérez, M. y otros (eds.): El Atlas de Carduchi de 1641 para la navegación del río Tajo del Ayuntamiento de Toledo. Estudio introductorio, vol. 1, Toledo, Ayuntamiento de Toledo, 2008.

García Tapia, N. y Vicente Maroto, M. I.: "Las escuelas de artillería y otras instituciones técnicas", en López Piñero, J. M. (dir.): Historia de la ciencia y de la técnica en la Corona de Castilla. Siglos XVI y XVII, vol. III, Salamanca, Junta de Castilla y León-Consejería de Educación y Cultura, 2002, pp. 73-81.

Garma y Salcedo, F. J.: Theatro Universal de España. Descripcion eclesiástica, y Secular de todos sus Reynos y Provincias, en General, y Particular, vol. 4, Barcelona, Imprenta de Mauro Martí, 1751.

Jack, M. A.: "The Accademia del Disegno in Late Renaissance Florence", The Sixteenth Century Journal, 7/2 (1976), pp. 3-20.

Lapuerta Montoya, M.: Los pintores de la corte de Felipe III: la Casa Real de El Pardo, Madrid, Fundación Caja Madrid, 2002. 
— "Bartolomé Carducho y Juan de Bolonia: arte y diplomacia en la corte de Felipe III", Anales de Historia del Arte, 7 (1997), pp. 157-182.

Llaguno y Amírola, E.: Noticias de los arquitectos y arquitectura de España desde su restauración, por el Excmo. Señor D. Eugenio Llaguno y Amirola, ilustradas y acrecentadas con notas, adiciones y documentos por D. Juan Agustín Ceán-Bermúdez, vol. 4, Madrid, Imprenta Real, 1829.

López Gómez, A.: La navegación por el Tajo. El reconocimiento de Carduchi y otros proyectos, Madrid, Real Academia de la Historia, 1998.

Marías, F.: "Teoría e historia en el tratado de arquitectura de Salvador Muñoz", en Madrid en el contexto de lo hispánico desde la época de los descubrimientos, vol. 2, Madrid, Universidad Complutense de Madrid-Departamento de Historia del Arte II, 1992, pp. 1445-1462.

Martín González, J. J.: “Arte y artistas del siglo XVII en la Corte”, Archivo Español de Arte, 31-122 (1958), pp. 125-142.

- Escultura barroca en España 1600-1700, Madrid, Ediciones Cátedra.

Mazón de la Torre, M. A.: "Las partidas de bautismo de Eugenio Cajés, de Félix Castelo, de los hermanos Rizi y otras noticias sobre artistas madrileños de la primera mitad del siglo XVII", Archivo Español de Arte, 176 (1971), pp. 413-425.

Molina Campuzano, M.: Planos de Madrid de los siglos XVII y XVIII, Madrid, Ministerio de Administraciones Públicas, 2002.

Moralejo Ortega, M.: "Zuccari and the Carduchos", en Andrews, J., Roe, J. y Noble Wood, O. (eds.): On Art and Painting. Vicente Carducho and Baroque Spain, Cardiff, University of Wales Press, 2016, pp. 205-221.

Navarro Brotóns, V.: “Carduchi, Luis”, en López Piñero, J. M. y otros.: Diccionario histórico de la ciencia moderna en España, vol. 1, Barcelona, Península, 1983, pp. 180-181.

Pérez de Herrera, C.: Discursos del Amparo de los legitimos pobres; y reducción de los fingidos: y de la fundación y principio de los Albergues destos Reynos, y amparo de la milicia dellos, Madrid, Por Luis Sánchez, 1598.

Pérez Preciado, J. J.: El marqués de Leganés y las artes, Tesis doctoral, Madrid, Universidad Complutense de Madrid, 2010.

Picatoste, F.: Apuntes para una biblioteca cientifica española del siglo XVI: estudios biográficos y bibliográficos de ciencias exactas, fisicas y naturales y sus inmediatas aplicaciones en dicho siglo, Madrid, Imprenta y Fundición de Manuel Tello, 1891.

Portús Pérez, J. (ed.): Velázquez y la familia de Felipe IV, Madrid, Museo Nacional del Prado, 2013.

Ricardvs, C.: Evclidis Elementorvm Geometricorvm Libros Tredecim Isidorvm et Hypsiclem \& Recentiores de Corporibus Regularibus, \& Procli Propositiones Geomtricas [...], Amberes, Ex Officina Hieronymi Verdvsii, 1645.

Rodríguez G. de Ceballos, A.: “Alonso Cano y el retablo”, en Álvarez Lopera, J. y otros: Figuras e imágenes del Barroco. Estudios sobre el barroco español y sobre la obra de Alonso Cano, Madrid, Argentaria-Visor Ed., 1999, pp. 251-270.

Roe, J.: "La biblioteca del conde-duque de Olivares y la geografía de la imaginación barroca", en Noble Wood, O., J. Roe, J. y Lawrence, J. (dirs.), Poder y saber. Bibliotecas y bibliofilia en la época del conde-duque de Olivares, Madrid, Centro de Estudios Europa Hispánica, 2011, pp. 261-276.

Sánchez Martín, F. J.: Método de geometría (1640) de Juan Carlos della Faille. Estudio y edición, Murcia, Editum Signos, 2019.

San Nicolás, Fray L. de: Segunda parte del arte y vso de architectvra. Dedicada al desamparo que padecio mi redemptor Iesvchristo las tres oras que estuvo viuo enclavado en 
el Arbol de la Cruz. Con el Qvinto y Septimo libros de Euclides traducidos de latin en Romance y las medidas dificiles de Bouedas y de las superficies y pies cubidos de Pichinas. Con las ordenanzas de la Imperial Ciudad de Toledo aprobadas y confirmadas por la Cesarea Mag.d del S.r Emperador Carlos V. de Gloriosa memoria [...] 1663 [1665].

Van de Vyver, O.: "Lettres de J.-Ch. della Faille S. I., Cosmographe du Roi à Madrid, à M.-F. van Langren, Cosmographe du Roi à Bruxelles 1634-1645", Archivum Historicum Societatis Iesu, 46 (1977), pp. 73-183.

Vicente Maroto, M. I., Esteban Piñeiro, M.: Aspectos de la ciencia aplicada en la España del Siglo de Oro, Valladolid, Junta de Castilla y León-Consejería de Cultura y Turismo, 2006. Westfall, R.: "Science and patronage: Galileo and the telescope", Isis 76 (1985), pp. 11-33. Yeves Andrés, J. A.: Encuadernaciones Heráldicas de la Biblioteca Lázaro Galdiano, Madrid, Ollero y Ramos - Fundación Lázaro Galdiano, 2008. 